\title{
A Review on Zinc Sulphide Thin Film Fabrication for Various Applications Based on Doping Elements
}

\author{
Md. Anisuzzaman Shakil'1, Sangita Das ${ }^{1}$, Md. Ashiqur Rahman'1, Umma Salma Akther ${ }^{1}$, \\ Md. Kamrul Hassan Majumdar,3, Md. Khalilur Rahman",4 \\ ${ }^{1}$ Department of Physics, Comilla University, Comilla, Bangladesh \\ ${ }^{2}$ Department of Computer Science and Engineering, Comilla University, Comilla, Bangladesh \\ ${ }^{3}$ Department of Electrical and Computer Engineering, Boise State University, Boise, ID, USA \\ ${ }^{4}$ Department of Electronic Materials and Devices Engineering, Soonchunhyang University, \\ Asan Chungnam, South Korea \\ Email: khalilphys@cou.ac.bd
}

How to cite this paper: Shakil, A.M., Das, S., Rahman, A.M., Akther, U.S., Hassan, K.M. and Rahman, K.M. (2018) A Review on Zinc Sulphide Thin Film Fabrication for Various Applications Based on Doping Elements. Materials Sciences and Applications, 9, 751-778.

https://doi.org/10.4236/msa.2018.99055

Received: June 4, 2018

Accepted: August 25, 2018

Published: August 28, 2018

Copyright (c) 2018 by authors and Scientific Research Publishing Inc. This work is licensed under the Creative Commons Attribution International License (CC BY 4.0).

http://creativecommons.org/licenses/by/4.0/

\begin{abstract}
Zinc Sulfide $(\mathrm{ZnS})$ thin film has attracted increasing attention due to their potential applications in the new generation of nano-electronics and optoelectronics devices. The physical and chemical properties of $\mathrm{ZnS}$ have outstanding quality for different applications. Moreover, $\mathrm{ZnS}$ doped with various elements are creating a new era for both academic research and industrial applications. So, the optical properties of modified $\mathrm{ZnS}$ thin film will help us to find a suitable doping element for convenient deposition which may enhance the conductance and transmitting properties of the film. This review work has been carried out to explore the four-modification elements that constitute $\mathrm{Cu}, \mathrm{Ni}, \mathrm{Co} \& \mathrm{Fe}$ as descending order of atomic number corresponding to $\mathrm{Zn}$, along with some potential applications considering the recent research work with other doping elements too such as $\mathrm{Al}, \mathrm{C}$, Pt etc. For example, FE, FET, Catalytic, Solar cell, Electroluminescence, Fuel cell, different sensors (Chemical sensors, Biosensors, Humidity sensors, light sensors, UV light sensors) and nanogenerators use $\mathrm{ZnS}$ thin film.
\end{abstract}

\section{Keywords}

ZnS, ZnS Properties, Doping Elements (Cu, Ni, Co, Fe), Sensors, Generators

\section{Introduction}

Nanomaterials and nanostructures play the important role to increase the device 
functionalities of nanoscience in the fields of energy sources, environments, and health [1]. Nanomaterials are increasingly gaining the attention of not only the scientific community but also the public due to their unique properties, which lead to new and exciting applications [2] [3] [4]. For the last few years the investigation has been focused on the preparation and characterization of II-VI semiconductor nanoparticles for applications in biological field as molecular probes or bio labels [5] and also have attracted much attention in photo and electroluminescence properties because of their size-dependent (which is tunable) and have promising optoelectronic applications [6]. Among these families, a nontoxic semiconductor zinc sulfide ( $\mathrm{ZnS}$ ) is one of the most important and typical crystalline phosphors for both applications and basic research. In particular, doped-ZnS phosphors have been investigated extensively, because ZnS, a good host material, is an important versatile and luminescent material with a wide band gap $(3.6 \mathrm{eV})$. The optical properties of various $\mathrm{ZnS}$ doped nanocrystals and the potential applications of these luminescent materials have been reported by different groups [7]. ZnS nanoparticles in their doped and co-doped form with transition and inner transition metals have received much attention as a class of particularly luminescent materials. Different metal ions such as $\mathrm{Cu}, \mathrm{Ni}, \mathrm{Co}, \mathrm{Fe}$, $\mathrm{Mn}, \mathrm{Pb}, \mathrm{Co}, \mathrm{Cd}, \mathrm{Eu}$, and $\mathrm{Sm}$ etc. doped with $\mathrm{ZnS}$ have been studied by many researchers because of their extensive photoluminescence (PL) properties [8]. Generally, ZnS doped with these metal ions provides new opportunities as full-color luminescence in the UV-visible region which used for various applications as well as research purposes. Now as traditionally shown remarkable fundamental properties versatility, it has a promise for novel diverse applications, including light-emitting diodes (LEDs), electroluminescence, flat panel displays, infrared windows, sensors, lasers, and biodevices, etc. Its atomic structure and chemical properties are comparable to more popular and widely known $\mathrm{ZnO}$. However, certain properties pertaining to $\mathrm{ZnS}$ are unique and advantageous compared to $\mathrm{ZnO}$. To name a few, $\mathrm{ZnS}$ has a larger bandgap of $3.68 \mathrm{eV}$ and 3.91 $\mathrm{eV}$ for cubic zincblende (ZB) and hexagonal wurtzite (WZ) ZnS, respectively, than $\mathrm{ZnO}(3.4 \mathrm{eV})$ and therefore it is more suitable for visible-blind ultraviolet (UV)-light based devices such as sensors/photodetectors [9]. On the other hand, $\mathrm{ZnS}$ is traditionally the most suitable candidate for electroluminescence devices [10].

Beside this, $\mathrm{ZnS}$ is considered one of the best materials for the CIGS solar cells among possible alternative buffer layers. In comparison with $\mathrm{CdS}$, the advantages of $\mathrm{ZnS}$ include its non-toxic and environmentally safe handling as well as its ability to provide better lattice matching to CIGS absorbers having energy band gaps in the range of 1.3 to $1.5 \mathrm{eV}$ compared with $\mathrm{CdS}$ and having a wider energy band gap compared with CdS, which transmits even higher energy photons and increases the light absorption in the absorber layer [11]. Recently, ZnS scintillation detectors have even been used in the potential detection of dark electric matter objects (DAEMONS) [12]. These objects can catalyze the fusion of light 
nuclei, suggesting new ways for solving the problem of deficiency of solar neutrinos and of solar energetic as a whole. The specific aim of this review work is to find novel potential applications of $\mathrm{ZnS}$ and also to compare the properties of $\mathrm{ZnS}$ doping with various elements. This review article contains four doping elements for $\mathrm{ZnS}$ thin film $\mathrm{Cu}, \mathrm{Ni}, \mathrm{Co} \& \mathrm{Fe}$ as descending order of atomic number matching with Zn's atomic number along with possible comparisons among them. Moreover, potential applications of $\mathrm{ZnS}$ are also added based on above-doing elements as well as other elements.

\section{Doping with Different Elements}

\subsection{Cu (Atomic No-29) Doped ZnS Thin Films}

$\mathrm{Cu}$ is an important impurity in II-VI compounds. Even though it has bad corrosion resistance but doped with other elements or compound, it improved excellent corrosion resistance and applicable various potential applications [13]. For example, $\mathrm{Cu}$-doped $\mathrm{ZnS}$ thin films were prepared using a wet chemical route and dip-coating process [14]. The study was made with a formula of $\mathrm{Zn}_{1-\mathrm{x}} \mathrm{Cu}_{\mathrm{x}} \mathrm{S}$ for $(0 \leq \mathrm{x} \leq 0.2)$ where $\mathrm{x}$ is the copper doping ratio into $\mathrm{ZnS}$. It was found that the XRD peaks were (111), (220) and (311) intense peak in (111) with increasing concentration where pure polycrystalline $\mathrm{ZnS}$ phase with cubic structure was preferred orientation along (111) plane Figure 1. The XRD pattern shows that when the $\mathrm{Cu}$ doping ratio was increased, the (111) peak becomes stronger and no significant change in diffraction angles with a noticeable increment in the intensity especially for high doping ratio of $10 \%$ and $20 \% \mathrm{Cu}$. This may be attributed to the closer ionic radius of $\mathrm{Zn}^{2+}(0.74 \mathrm{~A})$ and $\mathrm{Cu}^{2+}(0.73 \mathrm{~A})$.

From SEM the average Grain size is estimated as $60-100 \mathrm{~nm}$. The EDS spectrum of the films showed that the thin films contained $\mathrm{Zn}, \mathrm{Cu}, \mathrm{Si}, \mathrm{O}$ and $\mathrm{S}$ elements without any impurity Figure $1(\mathrm{~b})$. The presence of $\mathrm{Si}$ and $\mathrm{O}$ elements are expected due to the use of a glass substrate. Figure 2 shows that Eg gradually decreased from 3.60 to $3.32 \mathrm{eV}$ with increasing $\mathrm{Cu}$ dopant content is very attractive for LED, Solar cells and detector applications because the light emission and absorption region of the optical spectrum can be controlled by doping level. The average crystallite size of the prepared films varied between 13 and $21 \mathrm{~nm}$ depending on the $\mathrm{Cu}$ doping ratio as seen in Table 1. It was observed that when $\mathrm{Cu}$ doping ratio is much more than 5\% (10 and 20 at\%), the intensity of the (111) peak surprisingly increased and the crystalline quality greatly improved. Table 1 shows bandgap, crystallite size and film thickness values for varies doping ratio.

In Optical Analysis, the films were grown with 0 and 3 at\% $\mathrm{Cu}$ doping had a good average optical transmittance over $70 \%$ in the visible range. The transmittance, however, was slightly reduced as the $\mathrm{Cu}$ content increased probably due to the free hole absorption effect. The increased absorption by $\mathrm{Cu}$ dopant is a proof of the increased film thickness. The optical absorbance also increased with increasing film thickness and $\mathrm{Cu}$-doping ratio. This could be explained by the fact 


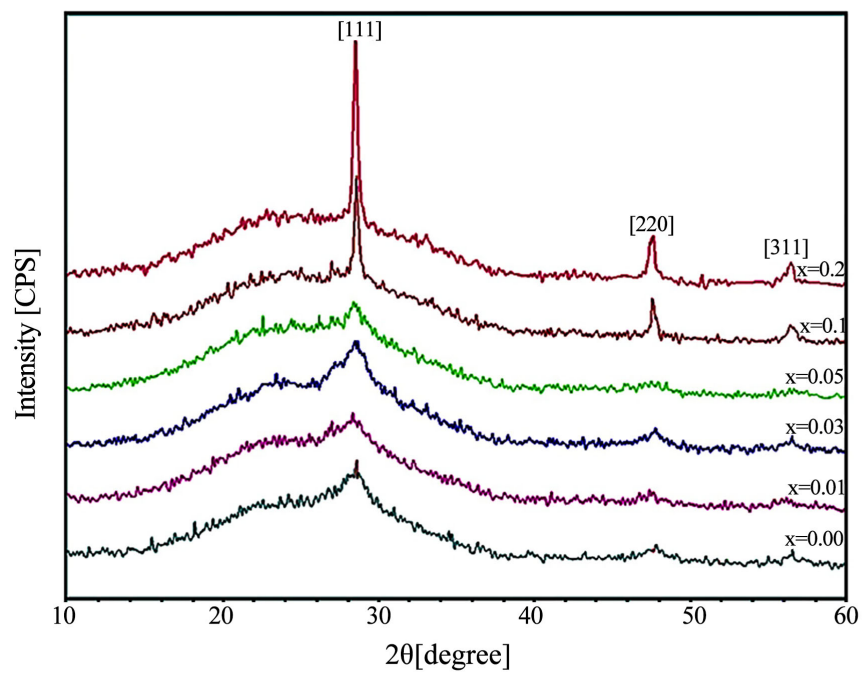

(a)

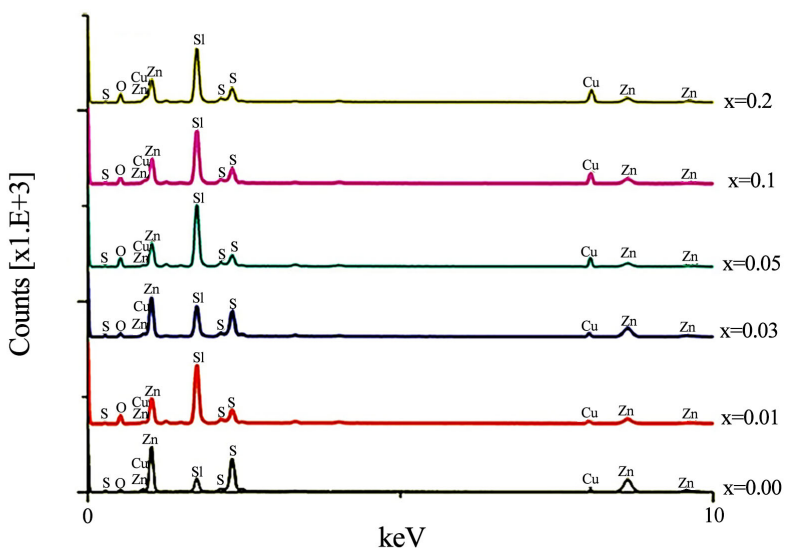

(b)

Figure 1. (a) XRD patterns of the $\mathrm{Zn}_{1-\mathrm{x}} \mathrm{Cu}_{\mathrm{x}} \mathrm{S}(\mathrm{x}=0.00,0.01,0.03,0.05,0.1$ and 0.2$)$ thin films; (b) EDS spectra of the $\mathrm{Zn}_{1-\mathrm{x}} \mathrm{Cu}_{\mathrm{x}} \mathrm{S}(\mathrm{x}$ $=0.00,0.01,0.03,0.05,0.1$ and 0.2$)$ thin films.

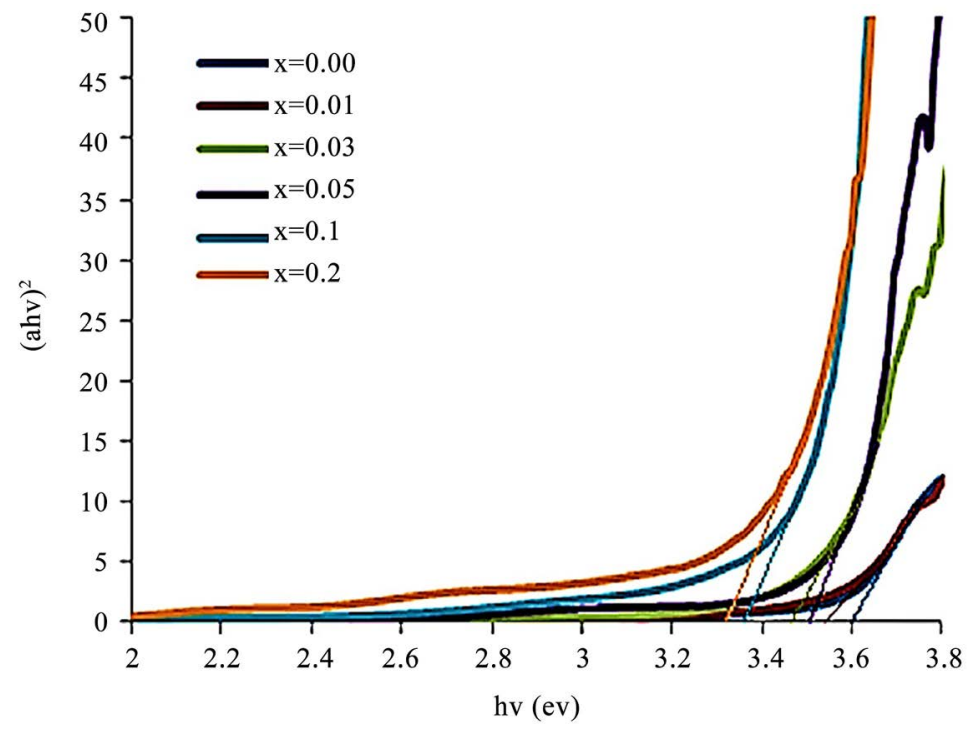

Figure 2. $(\mathrm{ah} v)^{2}$ dependence on the incident photon energy $\mathrm{h} v$ for the $\mathrm{Zn}_{1-\mathrm{x}} \mathrm{Cu}_{\mathrm{x}} \mathrm{S}(\mathrm{x}=0.00$, $0.01,0.03,0.05,0.1$ and 0.2 ) thin films.

Table 1. Cu doping ratio effect of $\mathrm{ZnS}$ in bandgap and crystallite size.

\begin{tabular}{cccc}
\hline Cu concentration (\%) & Bandgap (eV) & Crystallite size (nm) & Film Thickness (nm) \\
\hline $\mathrm{x}=0.00$ & 3.60 & 13 & 400 \\
$\mathrm{x}=0.01$ & 3.55 & 12 & 415 \\
$\mathrm{x}=0.03$ & 3.49 & 9 & 435 \\
$\mathrm{x}=0.05$ & 3.47 & 11 & 500 \\
$\mathrm{x}=0.1$ & 3.35 & 21 & 610 \\
$\mathrm{x}=0.2$ & 3.32 & 20 & 750
\end{tabular}


that in thicker films more atoms are present in the film and thus, more states will be available for the photons to be absorbed. The refractive index (n) decreases with increasing $\mathrm{Cu}$ content and film thickness Figure 3(a), whereas the extinction coefficient $(\mathrm{k})$ increases with increased $\mathrm{Cu}$ content and film thickness Figure 3 (b) by increasing the wavelength, $n$ decreases while $k$ increases.

In electrical analysis, the resistivity $\left(\rho>10^{6} \Omega \mathrm{cm}\right.$ ) of the undoped and doped $\mathrm{ZnS}(0 \%, 1 \%, 3 \%$ and $5 \% \mathrm{Cu})$ associated with the grain boundary effects of the polycrystalline nature of the films. And the resistivity decreased $5.61 \times 10^{5}$ to $4.72 \times 10^{3} \Omega \mathrm{cm}$ in $\mathrm{Cu}$-doping level from $10 \%$ to $20 \%$. This could be due to the fact that the increased $\mathrm{Cu}$ dopant results in new doping levels in the band gap of the host [14]. The poor crystalline quality of the films that consist of a few atomic layers of disordered atoms causes defects because of incomplete atomic bonding. The origin of the decreasing resistivity in highly $\mathrm{Cu}$ doped (10 \& 20 at\%) films can be contributed to the improved crystalline quality of the films. It can be concluded that the observed results for the produced $\mathrm{Cu}$ doped $\mathrm{ZnS}$ thin films will find a wide application in the optoelectronic devices.

\section{Cu Doped ZnS Thin Film with Effective Surfactants}

$\mathrm{ZnS}$ nanoparticle with varying initial doping concentration $(0.25 \%-1.25 \%)$ of $\mathrm{Cu}^{2+}$ was synthesized through a chemical precipitation method. To promote a confined and stable growth $\mathrm{ZnS}: \mathrm{Cu}^{2+}$ nanoparticles, the capping molecules trioctylphosphine oxide (TOPO), Sodium hexametaphosphate (SHMP) and polyethylene glycol (PEG) were used in the reaction process.

The sample exhibited absorption peaks at approximately $280 \mathrm{~nm}(4.43 \mathrm{eV})$, $296 \mathrm{~nm}(4.2 \mathrm{eV})$ and $310 \mathrm{~nm}(4.0 \mathrm{eV})$ for TOPO, SHMP and PEG-Capped $\mathrm{ZnS}: \mathrm{Cu}^{2+}$ nanoparticles respectively in Figure 4. The absorption peaks of the surfactant-capped particles were significantly blue-shifted compared to the uncapped particles and bulk ZnS which might be due to the reduction of particle size. This large blue shift could be attributed to the combined effect of the optical transition

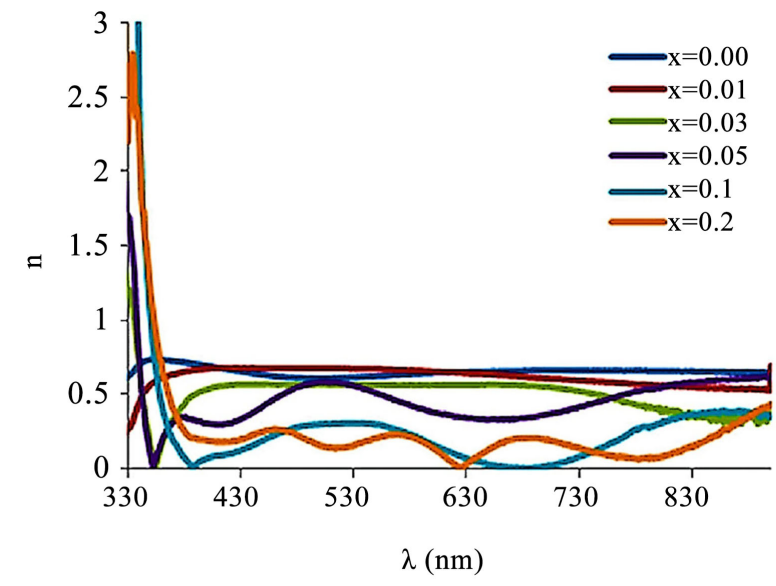

(a)

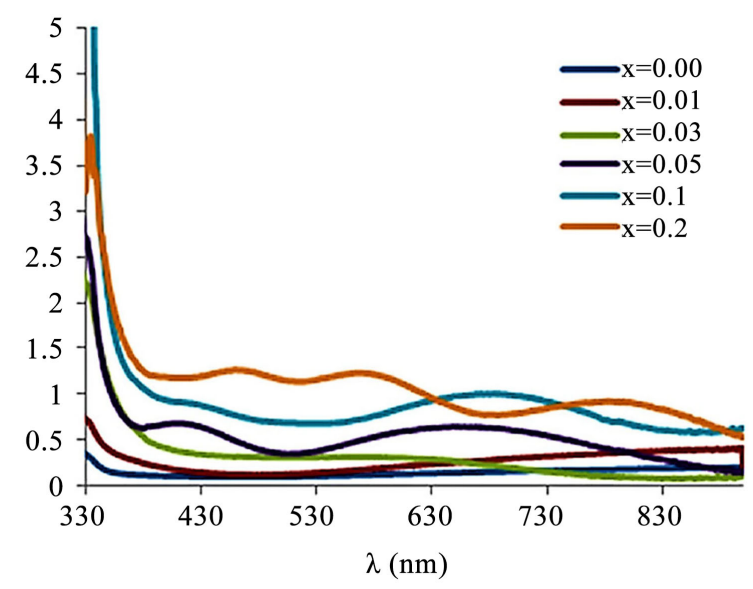

(b)

Figure 3. Wavelength depended refractive index (a) and extinction coefficient; (b) for the $\mathrm{Zn}_{1-\mathrm{x}} \mathrm{Cu}_{\mathrm{x}} \mathrm{S}(\mathrm{x}=0.00,0.01,0.03,0.05,0.1$ and 0.2) thin films. 


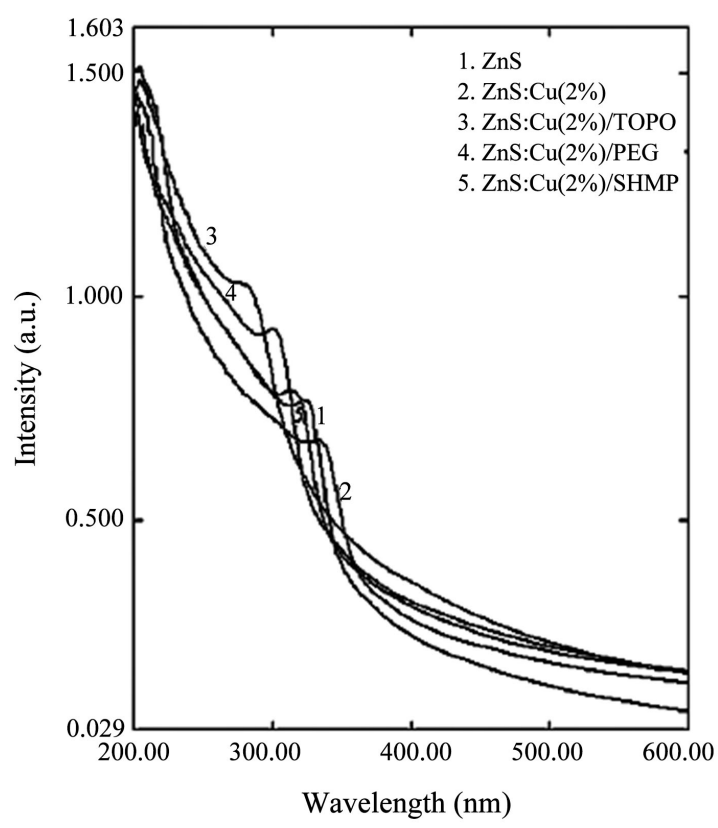

Figure 4. UV-visible absorption spectra of undoped $\mathrm{ZnS}$, uncapped and surfactant capped $\mathrm{ZnS}: \mathrm{Cu}^{2+}$ nanoparticles.

to the excitonic state of the $\mathrm{ZnS}: \mathrm{Cu}^{2+}$ nanoparticles. Figure 5 shows the $\mathrm{XRD}$ patterns of the undoped $\mathrm{Cu}^{2+}(0.25-1.25) \%$ dopant $\mathrm{ZnS}$ and surfactant (TOPO, SHMP and PEG) capped $\mathrm{ZnS}: \mathrm{Cu}^{2+}(0.5 \%)$ samples. The XRD pattern reveals that the particles exhibited pure cubic crystal structure. The estimated size of the uncapped and surfactant capped nanoparticles was $3.2-5.3 \mathrm{~nm}$.

TEM images of uncapped $\mathrm{ZnS}$ show that the resulting particles were uniformly spherical shaped particles with a narrow size distribution. However, the particles were aggregated due to the absence of capping agent. The surfactant capped particles Figures 6(b)-(d) were highly monodispersed and very small, which necessitates the use of capping agents for the synthesis of homogenous nanoparticles. Notably, the $\mathrm{ZnS}: \mathrm{Cu}^{2+}$ passivated with TOPO Figure 6(b) were well dispersed with smaller sizes than the other surfactant capped particles. This shows that the TOPO molecules not only control the particle growth $\mathrm{ZnS}: \mathrm{Cu}^{2+}$ but also reduce the particle size in an aqueous medium which may be due to the presence of the three hydrocarbon chains in TOPO molecules, resulting in a local trigonal symmetry and a large permanent dipole moment of the phosphorus-oxygen band. TOPO acts as a solvent as well as a surfactant and the resulting isolated particles were small.

Figure 7(a) shows the room temperature photoluminescence spectra of the

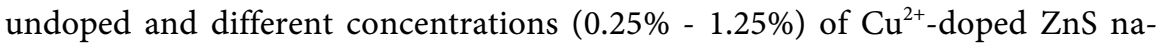
noparticles. When $\mathrm{Cu}^{2+}$ ions were doped into the $\mathrm{ZnS}$ nanoparticles, more defect states were introduced. Therefore, it is reasonable that the PL intensity is enhanced for the doped samples compared to the undoped samples. The broad and asymmetric emission of the doped samples may be due to uncontrolled particle growth caused by the absence of the capping agent. Figure $7(\mathrm{~b})$ shows that the 
emission peaks of the $\mathrm{Cu}^{2+}$-doped samples. Here with the increasing $\mathrm{Cu}^{2+}$ concentration from $0.75 \%$ to $1.00 \%$, the blue emission peak position is systematically shifted and converted to a single green emission (from 472 through 485, 497 to $500 \mathrm{~nm}$ ) peak. Further increasing the doping concentration from shifts the peak position to a longer wavelength with quenched intensity. Thus, it can be concluded that the $t_{2}$ energy level of $\mathrm{Cu}^{2+}$ ions are farther from the valence band

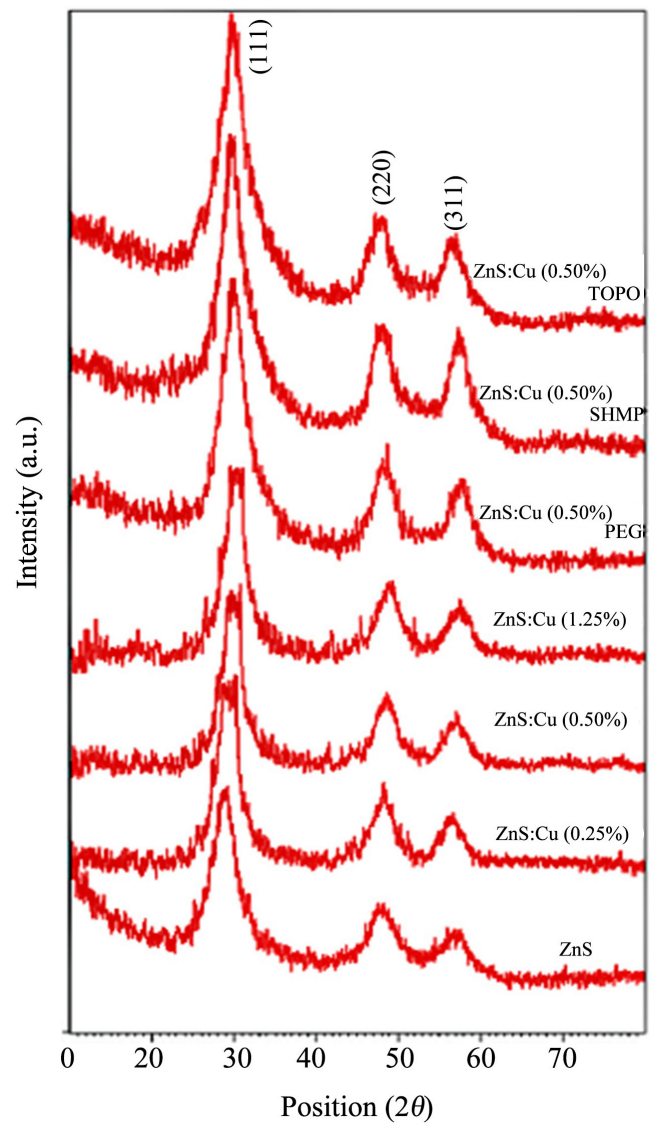

Figure 5. X-ray diffraction patterns of $\mathrm{ZnS}$, uncapped and surfactant-capped $\mathrm{ZnS}: \mathrm{Cu}^{2+}$ nanoparticles.

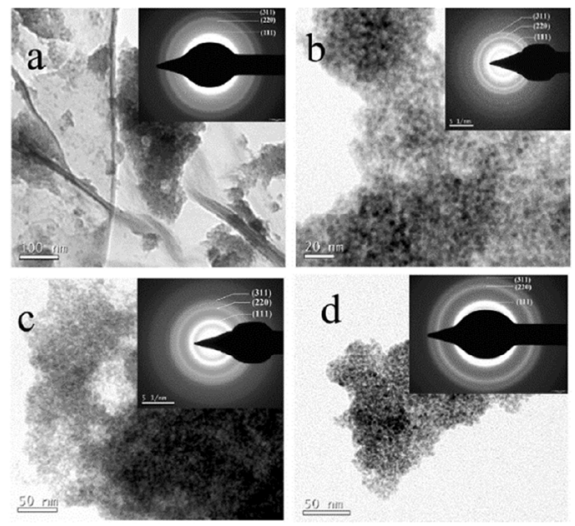

Figure 6. TEM micrographs of uncapped (a) TOPO-, (b) SHMP-, (c) and PEG-, (d) capped $\mathrm{ZnS}: \mathrm{Cu}^{2+}$ nanoparticles. 


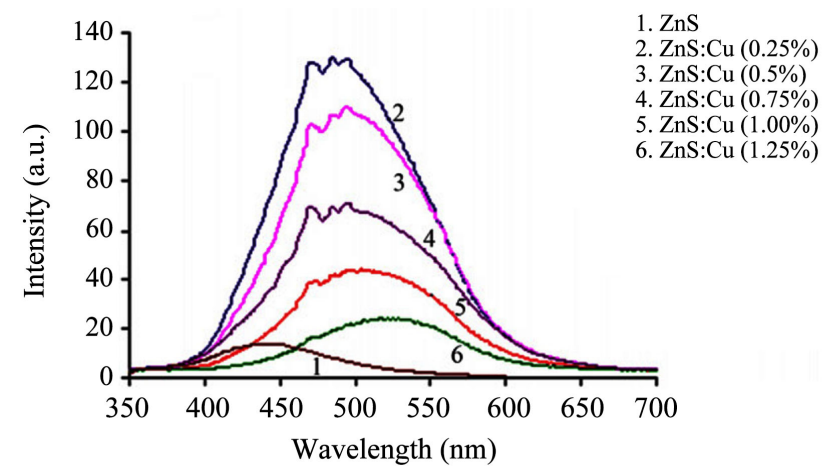

(a)

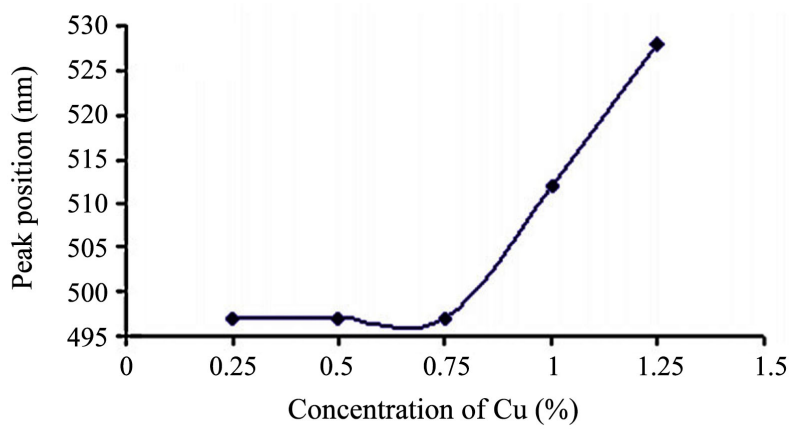

(b)

Figure 7. (a) PL spectra of undoped and various concentrations of $\mathrm{Cu}^{2+}(0.25 \%-1.25 \%)$ doped $\mathrm{ZnS}$ nanoparticles; (b) peak position versus concentration.

with increasing concentrations of $\mathrm{Cu}^{2+}$. Figure 8 shows that in the capped particles, the PL intensity is increased nearly 4 - 6 fold compared to the uncapped particles owing to an increase in radiative recombination efficiency based on passivation of the surfaces from broken surface bonds, adsorbed moisture and oxides. Compared to the PL emissions (capped particle), the TOPO-capped $\mathrm{ZnS}: \mathrm{Cu}^{2+}$ intensity is higher than the other surfactant-capped particles. This could be a unique characteristic of TOPO (which acts as the solvent as well as the capping agent). Moreover, the TOPO has a strong dipole moment from phosphorus-oxygen, which allows this compound to bind to metal ions. Because the TOPO molecules are completely covered on the $\mathrm{ZnS}: \mathrm{Cu}^{2+}$ surface, the surface defect is completely eliminated and the crystallinity is improved. Thus, it is concluded that the TOPO surfactant plays a vital role in the reduction of particle size and also the improvement of crystal quality, resulting in a narrow and enhanced PL emission. Moreover, as the increased PL intensity indicates the particle grows with a homogenous size distribution. Hence the results suggest the potential applications of the surfactant-capped $\mathrm{ZnS}: \mathrm{Cu}^{2+}$ nanoparticles in optoelectronic devices and nanoscale fluorescent probes for biological and medical applications [15].

\subsection{Ni (Atomic No-28) Doped ZnS Thin Films}

Pulsed laser deposition (PLD) was utilized to prepare $\mathrm{Ni}(2.5 \%$ and $5 \%)$ doped $\mathrm{ZnS}$ thin film at TS of $400^{\circ} \mathrm{C}$ on silicon (Si) and quartz substrates. The film is composed of well crystalline grain and grain looks quite uniform in Figure 9. The bandgap of the pristine and irradiated film is found to be $3.57 \mathrm{eV}$ and 3.49 $\mathrm{eV}$ for $2.5 \%$ and $5 \% \mathrm{Ni}$-doped $\mathrm{ZnS}$ thin films, respectively. These values are less as compared to those of bulk $\mathrm{ZnS}$, indicating the existence of more defect states in the bandgap. These defect states arise probably from the hybridization of host ZnS sp molecular orbitals with d orbitals of $\mathrm{Ni}$ substituted on $\mathrm{Zn}$ tetrahedral sites. These defect states lead to the tailing in the absorption at lower energy than the bandgap of the material. The tailing in absorption spectra makes it difficult to a precise determination of bandgap materials but allowing the possibility to 
determine the contribution of defect states. Optical absorption, XRD and TEM measurements indicate that $\mathrm{Ni}$ ions substituted to $\mathrm{Zn}$ on tetrahedral sites in these samples. XRD peaks assigned to the (100), (002), (110), and (112) lattice planes of the wurtzite (WZ) structure of $\mathrm{ZnS}$ and the crystallite size is found to be around $32 \mathrm{~nm}$. The films containing $2.5 \% \mathrm{Ni}$ are ferromagnetic up to $300 \mathrm{~K}$ and the magnetism of unpaired spins decreases at $5 \% \mathrm{Ni}$ content [16]. Figure 10

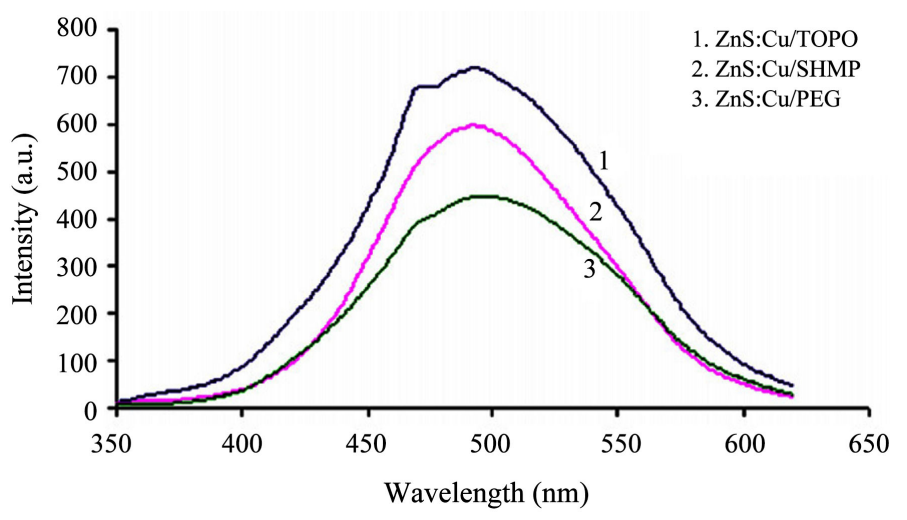

Figure 8. PL spectra of TOPO-, SHMP- and PEG-capped ZnS:Cu${ }^{2+}(0.5 \%)$ nanoparticles.
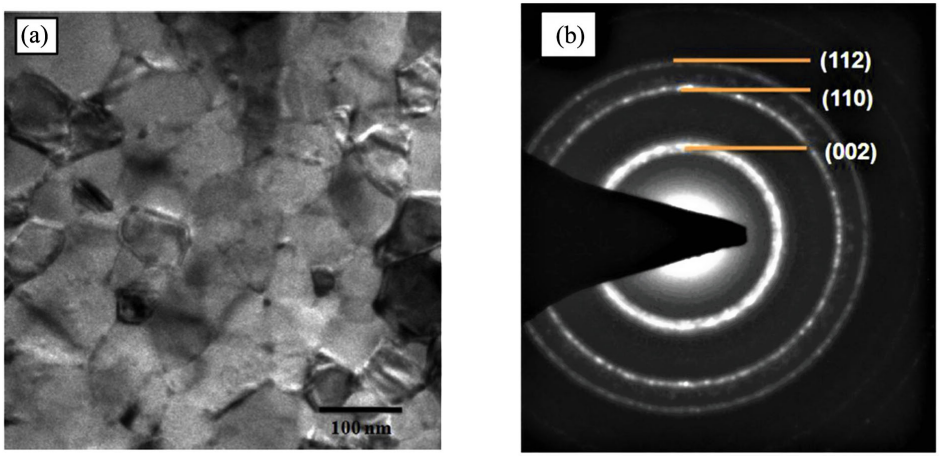

Figure 9. (a) Plane-section TEM images of 5\% Ni-doped ZnS thin film deposited at TS of $400^{\circ} \mathrm{C}$; (b) corresponding electron diffraction pattern of the film.

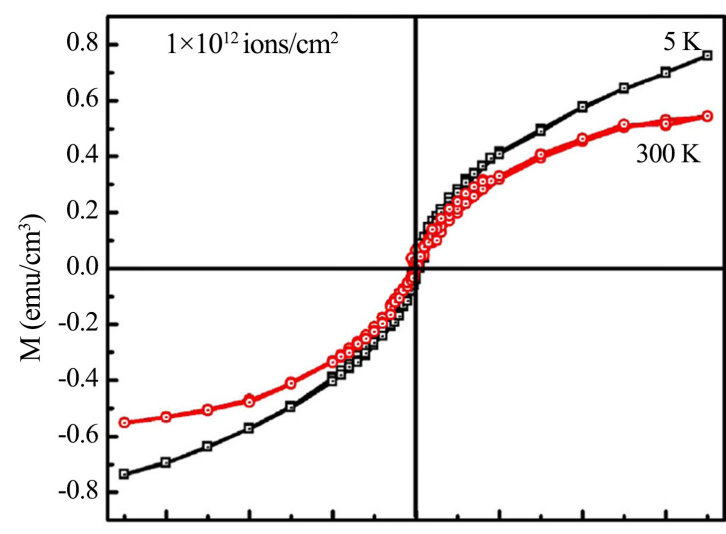

(a)

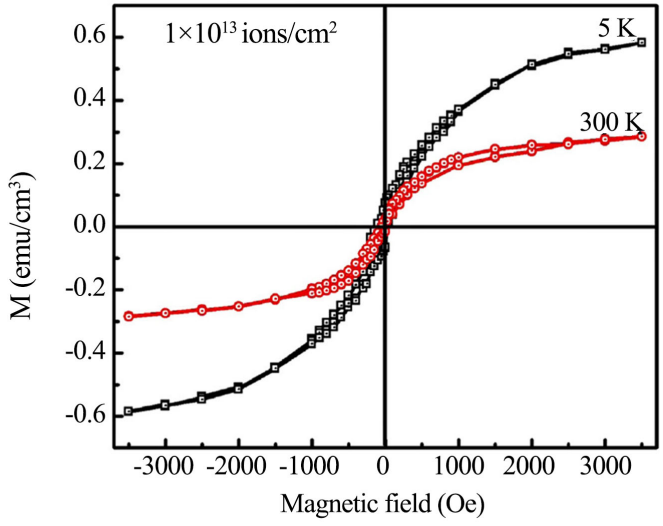

(b)

Figure 10. (a) and (b) show the hysteresis curves of magnetization $(\mathrm{M})$ as a function of magnetic field $(\mathrm{H})$ of $2.5 \%$ $\mathrm{Ni}$-doped $\mathrm{ZnS}$ thin film irradiated at a fluence of $1 \times 10^{12}$ ions $/ \mathrm{cm}^{2}$ and $1 \times 10^{13}$ ions $/ \mathrm{cm}^{2}$, respectively. 
shows that the magnetization decreases due to ion irradiation at both fluences. The decrease of magnetization due to ion irradiation could be explained based on the critical size of crystallites or change in density of structural defects. Therefore, structure disorder plays a major rule in the exchange coupling of the orbitals.

\subsection{Co (Atomic No-27) Doped ZnS Thin Films}

Co-doped nanocrystalline $\mathrm{ZnS}$ thin films on glass substrates carried out by $\mathrm{CBD}$ method [17]. TEM/HRTEM/SAED analysis confirmed the deposition of the polycrystalline cubic phase of ZnS. XRD peaks along (111), (220) and (311) lattice planes correspond to the standard pattern of cubic ZnS. The Crystallite size has an average value of $12 \mathrm{~nm}$. Value of lattice parameter "a" after doping is found to be smaller ( 5.382 to $5.306 \AA$ ) than that of pure $\mathrm{ZnS}(5.406 \AA$ ). The presence of cobalt in ZnS was confirmed by EDX analysis. The atomic ratios of cobalt extracted through EDX analysis were found to be 3.129247, 6.245236, 9.366940 and 12.53188 at\%. From HRTEM image the crystalline nature of the $\mathrm{ZnCoS}$ thin films and inter planner spacing d $0.30 \AA$ is confirmed. The average value of band gap was found to be $3.6 \mathrm{eV}$. A slight increment in the value of band energy is observed with increasing cobalt concentration as shown in Figure 11. This increment might be due to the structural modification after cobalt doping and occurrence of quantum confinement phenomenon.

The transmittance observed is in the range of $60 \%-80 \%$ in the visible region. The transmittance decreased slightly with increasing cobalt concentration that might be due to increase in crystallinity densification and surface roughness of the film. Noticeable point observed that all the films are highly transparent in the visible region of the optical spectrum where the peak transmittance noted $80 \%$ of this film. Figure 12 shows that PL spectra of thin films excited at $340 \mathrm{~nm}$ show two emission band at $380 \mathrm{~nm}$ and $510 \mathrm{~nm}$. The emission at the $380 \mathrm{~nm}$ result from the transition of an electron from shallow states near conduction band to the sulfur vacancies presents near the valance band in $\mathrm{ZnS}$ lattice. The luminescence centers of cobalt ions are formed when cobalt is incorporated into the $\mathrm{ZnS}$ host lattice. Since $\mathrm{Co}^{2+}$ is a sensitized agent and hence its presence in the host lattice would enhance the radiative recombination processes with the increase in doping concentration, the luminescence centers substantially increase which are then responsible for significant increase in PL intensity of green emission at $510 \mathrm{~nm}$. This observation reveals that cobalt ions substituted the zinc ions even at a higher doping concentration of 12 at $\%$ rather than staying at the surface or at interstitial positions.

Ferromagnetism in Co-doped ZnS is confirmed by DFT (Discrete Fourier Transform) calculations. The coercivity is observed to be invariable with cobalt concentrations of $6-12$ at\% having a value of 293 Oe. The hysteresis loop of the sample with $3 \%$ of cobalt is to be saturated, for the applied field of 9 kOe. Further increase in cobalt concentration, showed a systematic increase in the value 


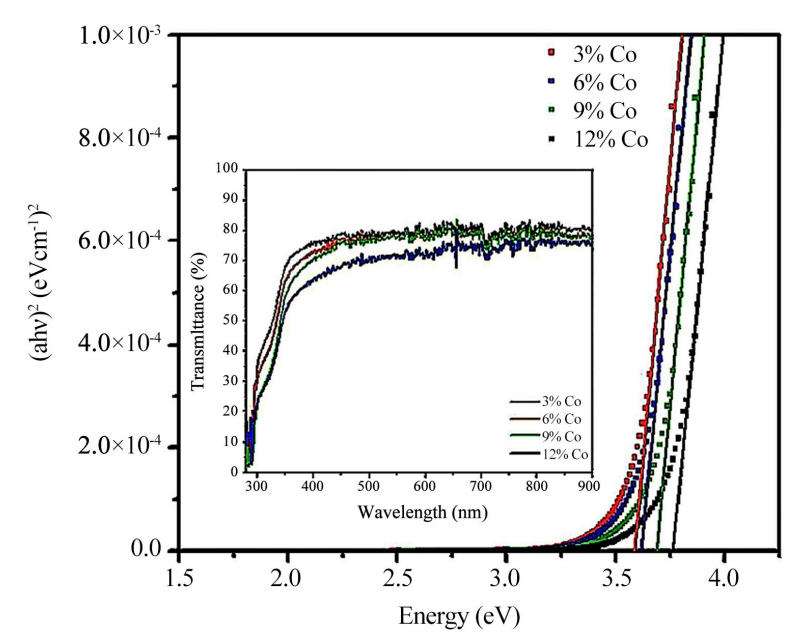

Figure 11. Band gap and transmission plots of cobalt doped $\mathrm{ZnS}$ thin films at different cobalt concentrations.

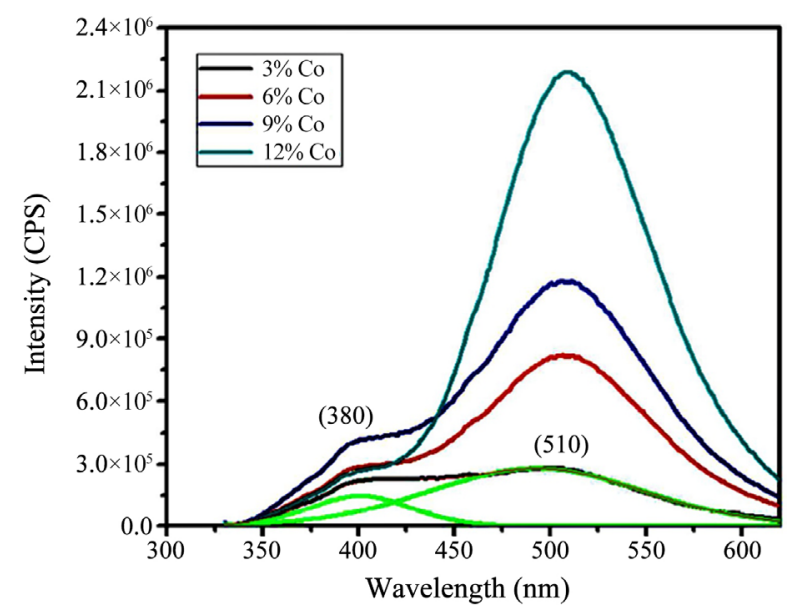

Figure 12. PL spectra of cobalt doped $\mathrm{ZnS}$ thin films at different cobalt concentrations.

of saturation magnetization. This systematic increment in magnetization may be due to the introduction of ferromagnetic ordering with increasing cobalt concentration in $\mathrm{ZnS}$ thin films. The retentivity for 6 at $\%$ concentration of cobalt is $9.33 \times 10^{-4} \mathrm{emu}$ and is observed to increase for 9 and 12 at $\%$ of cobalt concentration to $1.08 \times 10^{-3} \mathrm{emu}[18]$. The magnetic analysis reveals the presence of room temperature ferromagnetism in all samples. All of these results indicate that these films might have potential applications in advance optoelectronics and spintronics.

\subsection{Fe (Atomic No-26) Doped ZnS Thin Films}

Fe-doped $(\mathrm{Fe}=1 \%, 5 \%$ and $10 \%) \mathrm{ZnS}$ nanoparticles, synthesized via low temperature chemical route [18]. The average crystallite size has been found $\sim 10$ $\mathrm{nm}$. The TEM images indicated the average particle size as $\sim 9 \mathrm{~nm}$ in case undoped and doped samples with spherical symmetry. The HRTEM images give 
atomic spacing as $0.19 \mathrm{~nm}$ for undoped $\mathrm{ZnS}$ nanoparticles which accords well with the d-spacing value of (110) plane in XRD spectra standard ZnS. The corresponding atomic spacing in case of $10 \%$ Fe-doped ZnS. EDS spectra give observed amount of $\mathrm{Fe}$ in $1 \%, 5 \%$ and $10 \% \mathrm{Fe}$-doped $\mathrm{ZnS}$ is $0.73 \%, 4.05 \%$ and $7.40 \%$ respectively. It indicates that the observed amount is less as compared to the actual doped amount. It may be attributed to extensive washing of samples leading to a decrease in the observed percentage of doped $\mathrm{Fe}$.

In Figure 13 XRD peaks are corresponding to the (100), (002), (101), (110), (103) and (112) planes, which correspond to the hexagonal crystal structure. $\mathrm{XRD}$ peaks indicate the nanometer regime of undoped and $\mathrm{Fe}$ doped $\mathrm{ZnS}$ nanoparticles. The intensity of the peaks is reduced as the doping concentration is increased which indicates the deterioration of the structural quality of $\mathrm{ZnS}$ with $\mathrm{Fe}$ doping. From Table 2 it is clear that, as the Fe concentration is increased, the lattice parameter is slightly decreased which indicates that the Fe doped ZnS lattice is under compressive strain due to smaller radii of $\mathrm{Fe}^{2+}$ ions as compared to $\mathrm{Zn}^{2+}$ ions. The estimated crystallite size is $10.38 \mathrm{~nm}$ which accords well with TEM size. The band gap 3.86, 3.91, 3.94 and $3.98 \mathrm{eV}$ for $\mathrm{Fe}(0 \%, 1 \%, 5 \%, 10 \%)$ concentration respectively.

The UV-vis spectra of undoped and Fe-doped nanoparticles have been recorded $290 \mathrm{~nm}$ and $450 \mathrm{~nm}$ as shown in Figure 14. Table 3 shows that the absorption edge is blue shifted in the Fe doped $\mathrm{ZnS}$ nanoparticles as compared to the undoped counterpart. It may be due to the size of $\mathrm{Fe}^{2+}$ ions as compared to the $\mathrm{Zn}^{2+}$ ions. As the Fe concentration in $\mathrm{ZnS}$ matrix is increased the absorption edge is further blue-shifted as compared to the which may be attributed to fact that the doped Fe ions are forming new energy levels in the ZnS energy band. The PL emission spectra exhibit a peak at $422 \mathrm{~nm}$ corresponding to the blue emission shown in Figure 15 which may be attributed to radiative recombination between Sulphur vacancies related donor energy levels and purity phase of host $\mathrm{ZnS}$ material. It has been observed that the PL intensity of resultant $\mathrm{ZnS}$ nano structure is decreasing with the increasing Fe concentration which indicates that $\mathrm{Fe}^{2+}$ ions are acting as quenching centers. In the $\mathrm{Fe}$ doped $\mathrm{ZnS}$, the electron can occupy a tetrahedral cationic site and it may be captured by the $\mathrm{Fe}^{2+}$ ions in ${ }^{4} \mathrm{~T}_{1}$ level from which it may decay to ${ }^{6} \mathrm{~A}_{1}$ level by a normal recombination process, leading to the decrease in PL intensity. The M-H curve in Figure 16 shows that the magnetic behavior induced in the Fe-doped $\mathrm{ZnS}$ nanoparticles with well-resolved hysteresis loops whereas undoped $\mathrm{ZnS}$ nanoparticles indicate a diamagnetic type behavior. At 5\% Fe concentration a weak ferromagnetic or paramagnetic has been observed. All of these findings indicate that the Fe-doped $\mathrm{ZnS}$ nanoparticles can have future applications in solar cells, biomarkers, band gap engineering devices, lasers and nanoelectromechanical systems (NEMS) [18].

\subsection{Comparison of Doped ZnS Thin Films}

The properties of doped $\mathrm{ZnS}$ are varied with different doping element. And 
these phenomena can be easily manifested by comparing their properties in different articles for varies approaches of synthesis. But considerably, in all properties bandgap, crystallite size and crystal structure are comparable due to only these properties are mostly available in articles. And other properties testing was depended on the basic property of dopant element.

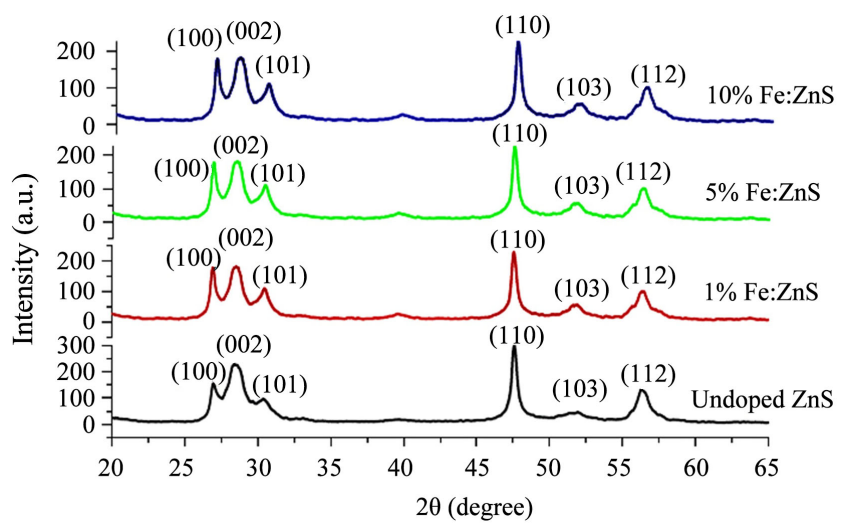

Figure 13. XRD patterns of undoped and Fe-doped ZnS nanoparticles.

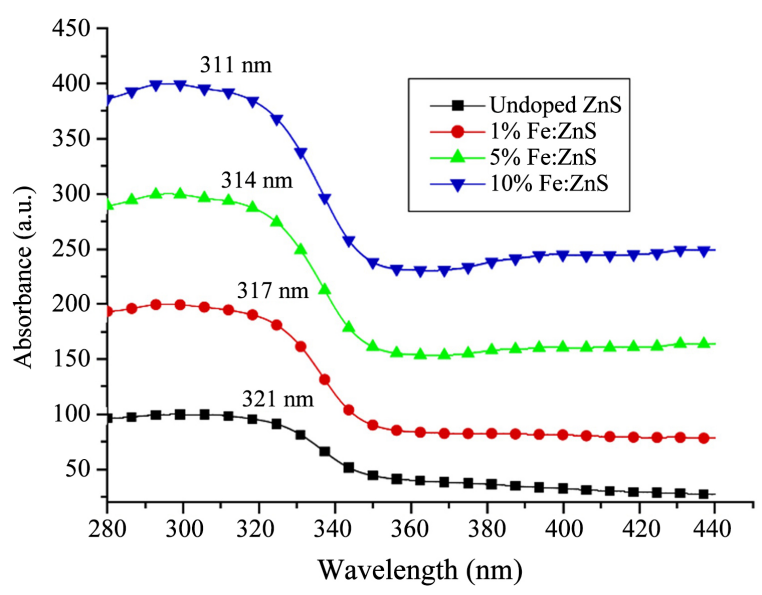

Figure 14. UV-Vis. spectra of undoped and Fe-doped ZnS nanoparticles.

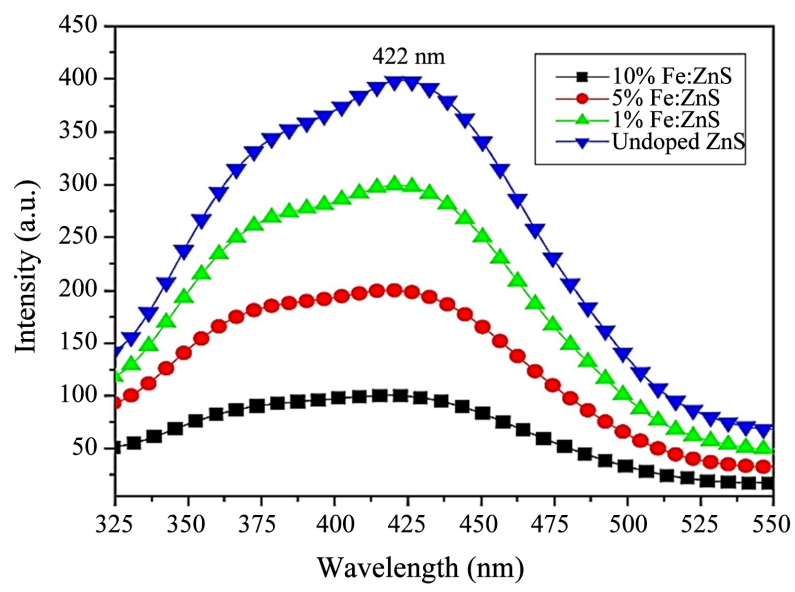

Figure 15. PL spectra of undoped and Fe-doped nanoparticles. 


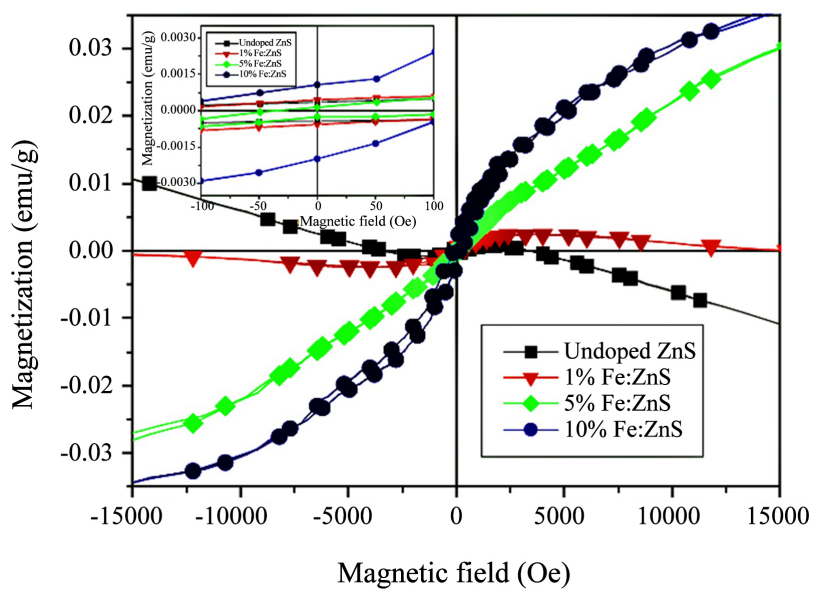

Figure 16. M-H curves of Fe-doped nanoparticles [inset magnified M-H curves].

Table 2. Variation of lattice parameters with Fe concentration in $\mathrm{ZnS}$ nanoparticles along (002) plane.

\begin{tabular}{cccc}
\hline Fe concentration $(\%)$ & Peak position & d-spacing $(\AA)$ & Lattice constants \\
\hline $\mathrm{x}=0.00$ & 28.34 & 3.18 & $\mathrm{a}=3.84, \mathrm{c}=6.25$ \\
$\mathrm{x}=0.01$ & 28.38 & 3.14 & $\mathrm{a}=3.81, \mathrm{c}=6.23$ \\
$\mathrm{x}=0.05$ & 28.47 & 3.11 & $\mathrm{a}=3.77, \mathrm{c}=6.19$ \\
$\mathrm{x}=0.1$ & 28.50 & 3.09 & $\mathrm{a}=3.75, \mathrm{c}=6.14$ \\
\hline
\end{tabular}

Table 3. Variation of band gap with Fe concentration.

\begin{tabular}{ccc}
\hline Fe concentration $(\%)$ & Absorption edge $(\mathrm{nm})$ & Band gap $(\mathrm{eV})$ \\
\hline $\mathrm{x}=0.00$ & 321 & 3.86 \\
$\mathrm{x}=0.01$ & 317 & 3.91 \\
$\mathrm{x}=0.05$ & 314 & 3.94 \\
$\mathrm{x}=0.1$ & 311 & 3.98 \\
\hline
\end{tabular}

Table 4 represented such a comparison where band gap measure for $5 \%$ concentration of doping element. Doped ZnS may have either cubic or hexagonal structure as zincblende (ZB) or wurtzite (WZ), which depends on its synthesis conditions such as synthesis temperature, precursor type and concentration. It is obvious from above table that Crystallite sizes are nearly equal for different types of doped but for $\mathrm{Ni}$, the changes occur might be due to deposition method which is pulsed layer deposition method (PLD). In the case of Fe-doped ZnS nanoparticles, crystallite size is small, but band gap is large which may be attributed to the small size of $\mathrm{Fe}^{2+}$ ions as compared to $\mathrm{Zn}^{2+}$ ions and formation of new energy levels in the ZnS [18]. Comparing all of the above modification it can be concluded that $\mathrm{Cu}$ doped $\mathrm{ZnS}$ thin film constitutes best for crystallite size that upholds $11 \mathrm{~nm}$ and also for band gap that is about $3.47 \mathrm{eV}$. The reason is that, if the crystallite size is small the grains will be more compact and dense in the film. 
Table 4. Comparison of $(\mathrm{Cu}, \mathrm{Ni}, \mathrm{Co}, \mathrm{Fe})$ doping in $\mathrm{ZnS}$ for some properties.

\begin{tabular}{ccccc}
\hline Property & Cu-Doped & Ni-doped & Co-Doped & Fe-Doped \\
\hline Atomic no & 29 & 28 & 27 & 26 \\
Band Gap & $3.47 \mathrm{eV}$ & $3.49 \mathrm{eV}$ & $3.6 \mathrm{eV}$ & $3.94 \mathrm{eV}$ \\
Crystallite Size & $11 \mathrm{~nm}$ & $32 \mathrm{~nm}$ & $12 \mathrm{~nm}$ & $10.38 \mathrm{~nm}$ \\
Structure & Zincblende (ZB) & Wurtzite (WZ) & Zincblende (ZB) & Wurtzite (WZ) \\
Structure type & Cubic & Hexagonal & Cubic & Hexagonal \\
\hline
\end{tabular}

The porosity between the grain will be small and one can easily get a uniform, dense and homogeneous surface which is one of the important precursors for the deposition of the thin film. Moreover, some similarities are also found observing these modified $\mathrm{ZnS}$ thin film. The transmittance of $\mathrm{Cu}$, Co, Fe doped thin film reduces as the content of these element increases probably due to the free hole absorption effect. Therefore, absorption increases with the rising doping concentration which could be explained on the fact that in the thicker film more atoms are present in the film and thus more states will be available for the photon to be absorbed. On the other hand, the effects of surfactants $\mathrm{ZnS}: \mathrm{Cu}^{2+}$ surface was also has been observed. The effective surfactants used here are TOPO, SHMP, PEG. Comparing among different properties of surfactants and without surfactants films it was observed that TOPO surfactants help to reduce the particle size significantly than SHMP and PEG. It also eliminates defects and improves the crystal quality.

\section{Potential Applications of ZnS}

Zinc Sulfide has numerous applications. Among them consideration is used as recent progress on the improvement of the properties of $\mathrm{ZnS}$ for finding novel potential applications are included below. Such applications are various ZnS nanostructures as field emitters, field effect transistors (FETs), catalyzers, Fuel cell, Electroluminescence devices, Solar cells, UV-light and chemical sensors, humidity and gas sensors, biosensor and nanogenerators etc.

\subsection{Field Emission (FE)}

Field-emission (FE) (also known as electron field-emission) is an emission of electron-induced by external electromagnetic fields. FE can take place from solid and liquid surfaces, or individual atoms into a vacuum or open air, or result from the promotion of electrons from the valence to the conduction band in semiconductors.

Figure 17(a) shows a graphic diagram of the FE phenomena [10]. Generally, a rod-like metal probe is used as an anode and the emitted objects serve as a cathode. This process involves the extraction of electrons from a solid by tunneling through the surface potential barrier. The emitters can have different tip geometries such as 1) round tip, 2) blunt tip and 3) conical tip, as manifested in Figure 
17(b). FE phenomena mostly studied at room temperature and are barely temperature dependent. The determining factors for the emission current could be the work function of the emitting materials, the local electric field, the distance between a sample and the anode, and the tip geometry, the work function of an emitter surface plays a primary role in the emission current. Table 5 lists the work functions of some important inorganic semiconductors and metals.

A mixture of commercial $\mathrm{ZnS}$ powders and $\mathrm{C}$ nanopowders and $\mathrm{S}$ powders was adopted as precursors instead of the previously used pure $\mathrm{ZnS}$ powders or Nanopowders [19] [20]. The evaporation and agglomeration rates were significantly decreased in this case compared with previous experiments. During the formation of ultrafine $\mathrm{ZnS}$ nanobelts, first, the $\mathrm{ZnS}$ powders and $\mathrm{C}$ nanopowders undergo a reaction: $2 \mathrm{ZnS}+\mathrm{C}=2 \mathrm{Zn}+\mathrm{CS}_{2}$, to gradually produce a $\mathrm{Zn}$ vapor. The $\mathrm{Zn}$ vapor reacts with $\mathrm{S}$ vapor to form nanobelts at a relatively moderate temperature $\left(1000^{\circ} \mathrm{C}\right)$. Superfluous $\mathrm{C}$ gas is also transferred to the relatively low-temperature zone and absorbs on the as-grown $\mathrm{ZnS}$ nanobelts, blocking the belt width. This leads to ultrafine $\mathrm{ZnS}$ nanobelt formation. Figure 18 shows SEM images of the as-grown nanobelts [21].

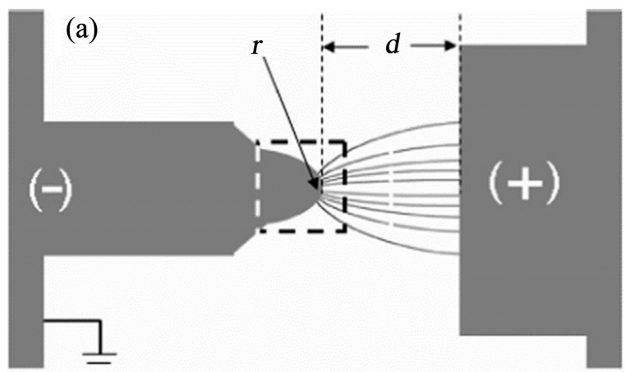

(b)

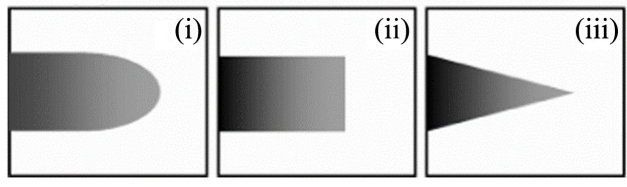

Figure 17. (a) A graphic diagram of field emission phenomenon, presenting the emission that arises from the tip of an emitter; (b) The emitters can have different tip geometry such as (i) round tip, (ii) blunt tip and (iii) conical tip, and so on [14].
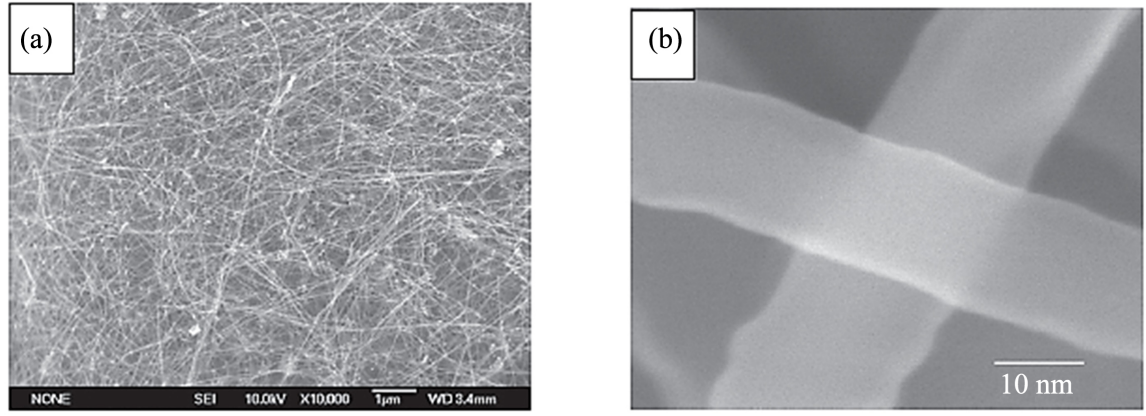

Figure 18. (a) and (b) Low-magnification and high-magnification SEM images, showing a uniform thick-ness and width of the structures over the entire length [21]. 
Table 5. The work function $\Phi$ of some important inorganic semiconductors, C nanotubes and metals.

\begin{tabular}{ccccccccccc}
\hline $\begin{array}{c}\text { Semiconductors and } \\
\text { C nanotubes }\end{array}$ & $\mathrm{ZnO}$ & $\mathrm{C}$ nanotubes & $\mathrm{AlN}$ & $\mathrm{WO}_{3}$ & $\mathrm{SiC}$ & $\mathrm{Si}$ & $\mathrm{GaN}$ & $\mathrm{GaAs}$ & $\mathrm{CdS}$ & $\mathrm{ZnS}$ \\
\hline Work function $(\mathrm{eV})$ & 5.3 & 5 & 3.7 & 5.7 & 4.0 & 3.6 & 4.1 & 4.77 & 4.2 & 7.0 \\
Metals & $\mathrm{Au}$ & $\mathrm{Ag}$ & $\mathrm{Al}$ & $\mathrm{W}$ & $\mathrm{Sn}$ & $\mathrm{Cu}$ & $\mathrm{Fe}$ & $\mathrm{Mo}$ & $\mathrm{Cd}$ & $\mathrm{Zn}$ \\
Work function $(\mathrm{eV})$ & 5.1 & 4.26 & 4.28 & 4.5 & 4.42 & 4.65 & 4.5 & 4.37 & 4.07 & 4.3 \\
\hline
\end{tabular}

As reviewed pure $\mathrm{ZnS}$ is not the best candidate for FE but a mixture of commercial $\mathrm{ZnS}$ powders and $\mathrm{C}$ powders and $\mathrm{S}$ powders which is known as ultrafine $\mathrm{ZnS}$ is successful as field emitters. These developed methods are not only facile to enhance the FE properties of $\mathrm{ZnS}$ nanostructure but also, they are general to develop other inorganic semiconducting nanostructures into potential field emitters.

\subsection{Field Effect Transistors (FETs)}

$\mathrm{ZnS} / \mathrm{SiO}_{2}$ core/shell nanocables are synthesized by a vapor-liquid-solid growth method to fabricate a FETs nanodevice. This device immersed in the liquid for biological and chemical sensing, by monitoring the electrical conductance during protein or chemical additions. Figure 19 shows the schematic of the sensor. Protein, such as bovine serum albumin (BSA) has a strong affinity to silica surface, which makes it possible to utilize the charged BSA as a gate. The nanocable-based transistor was immersed in a PB solution with bovine serum albumin BSA $0.0005 \mathrm{~g} / \mathrm{L}$ and its electrical conductance was decreased while proteins were added. The conductance was decreased upon stepwise exposure to BSA $(0.0005$ to $0.005 \mathrm{~g} / \mathrm{L}$ ), strongly suggesting that adsorption of BSA on the surface of the nanocable is responsible for the observed conductance change which used for real-time BSA protein detection.

Since the nanocable is $\mathrm{n}$-type, so the conductance of the device decreases when BSA is added to it. The conductance of the device, on the other hand, was found to increase when a positively charged protein was added [22].

\subsection{Catalytic Activities}

$\mathrm{ZnS}$ is a direct wide-gap semiconductor with remarkable chemical stability against oxidation and hydrolysis and these properties are retained when the particle size steps down to just a few nanometers. Therefore, nanoparticles of $\mathrm{ZnS}$ are interesting entities as a catalyst in environmental protection through the removal of organic and toxic water pollutants. $\mathrm{ZnS}$ nano-materials have been used for the photocatalytic degradation of organic pollutants such as dyes, p-nitrophenol, and halogenated benzene derivatives in wastewater treatment [23]. Photoreduction of $\mathrm{CO}_{2}$ to formic acid is more efficient in the presence of $\mathrm{Na}_{2} \mathrm{~S}$. The catalytic activity commences due to the post photoexcitation high reductive potential of electrons in $\mathrm{ZnS}$ ( $-1.75 \mathrm{~V}$ relative to a standard hydrogen electrode). The holes 
have an oxidative potential of about $+1.85 \mathrm{~V}$. It was found that the reduction never happened either in the dark or under the irradiation in the absence of $\mathrm{ZnS}$ suspensions [10]. These studies revealed that $\mathrm{ZnS}$ nanostructures are good photocatalysts due to rapid generation of electron-hole pairs by photo-excitation and highly negative reduction potentials of excited electrons.

\subsection{Fuel Cell}

ZnS nanoparticles had catalytic activity for the decomposition of ethanol, a potentially abundant fuel for mobile electricity generation since it could be fabricated by fermentation from a broad range of organic materials [24]. Electrocatalytic conversion of ethanol in the presence of $\mathrm{O}_{2}$ to form $\mathrm{H}_{2} \mathrm{O}$ and $\mathrm{CO}_{2}$ involves the transfer of 12 electrons per molecule of ethanol and proceeds via two intermediates, acetaldehyde and acetic acid. The free enthalpies of combustion associated with the individual species are described below:

$$
\begin{array}{lc}
\mathrm{C}_{2} \mathrm{H}_{5} \mathrm{OH}+0.5 \mathrm{O}_{2} \rightarrow \mathrm{CH}_{3} \mathrm{CHO}+\mathrm{H}_{2} \mathrm{O} & 190.5 \mathrm{~kJ} \cdot \mathrm{mol}^{-1} \\
\mathrm{CH}_{3} \mathrm{CHO}+0.5 \mathrm{O}_{2} \rightarrow \mathrm{CH}_{3} \mathrm{COOH} & 268.3 \mathrm{~kJ} \cdot \mathrm{mol}^{-1} \\
\mathrm{CH}_{3} \mathrm{COOH}+2 \mathrm{O}_{2} \rightarrow 2 \mathrm{CO}_{2}+2 \mathrm{H}_{2} \mathrm{O} & 849.8 \mathrm{~kJ} \cdot \mathrm{mol}^{-1} \\
\mathrm{C}_{2} \mathrm{H}_{5} \mathrm{OH}+3 \mathrm{O}_{2} \rightarrow 2 \mathrm{CO}_{2}+3 \mathrm{H}_{2} \mathrm{O} & 1308.6 \mathrm{~kJ} \cdot \mathrm{mol}^{-1}
\end{array}
$$

Comparison of these values with that of $\mathrm{ZnS}$ shows that $\mathrm{ZnS}$ should always be stable in the presence of ethanol against oxidation or reduction and therefore it could be a stable catalyst against ethanol oxidation. It is also important to cap $\mathrm{ZnS}$ nanostructures with small ligands in order to facilitate electron transfer across the surface.

In this setup of Figure 20, oxidation of ethanol took place only in the presence of $\mathrm{ZnS}$ particles. Electrodes without $\mathrm{ZnS}$ particles generated no current. Repeated ethanol addition increased the flowing current stepwise. A pure carbon electrode also led to a sharp current peak (adsorption of ethanol), but not to continuous decomposition, while with an ITO blank electrode, these effects were much smaller [24]. This work establishes the usability of $\mathrm{ZnS}$ nanoparticles as electro catalysts for direct conversion of ethanol into fuel cells. Such catalysts are the need of the hour since ethanol can be made from a broad variety of organic materials by fermentation.

\subsection{Nanogenerator}

Nanogenerators use piezoelectric properties to converted nanoscale mechanical energy into electrical energy. $\mathrm{ZnO}-\mathrm{ZnS}$ heterojunction nanowire arrays were synthesized by a thermal evaporation process with the presence of residual oxygen. Figure 21(a) shows the $\mathrm{ZnO}-\mathrm{ZnS}$ nanowire arrays and a three-dimensional voltage output image after an AFM scan across a heterostructure of $\mathrm{ZnO}-\mathrm{ZnS}$ nanowire arrays with an area of $30 \times 30 \mu \mathrm{m}^{2}$. Almost all the heterostructure nanowire arrays are uniform and grow vertically on the substrate. Piezoelectric responses of the heterostructure $\mathrm{ZnO}-\mathrm{ZnS}$ nanowire arrays were examined using 
AFM in contact mode with a conducting Pt-coated Si tip each peak represents an electric voltage/current that is generated by deflecting the corresponding nanowire, and output voltages are around $6 \mathrm{mV}$. Moreover, the voltage outputs of heterostructure $\mathrm{ZnO}-\mathrm{ZnS}$ nanowire arrays mainly result from the interaction between $\mathrm{W}-\mathrm{ZnO}$ and the $\mathrm{Pt}$ tip as $\mathrm{ZnO}$ is at the top part of the heterostructure $\mathrm{ZnO}-\mathrm{ZnS}$ nanowire arrays [25] [26].

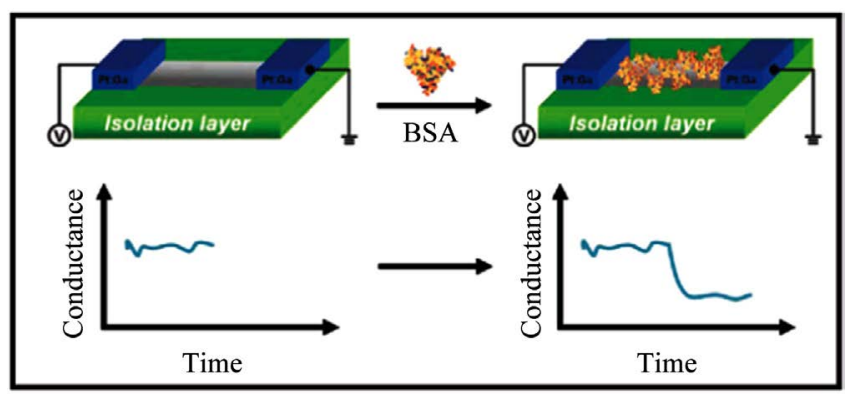

Figure 19. Schematic diagram of a FETs device acting as a sensor; the binding of BSA with a net negative charge is expected to yield a decrease in the conductance [22].

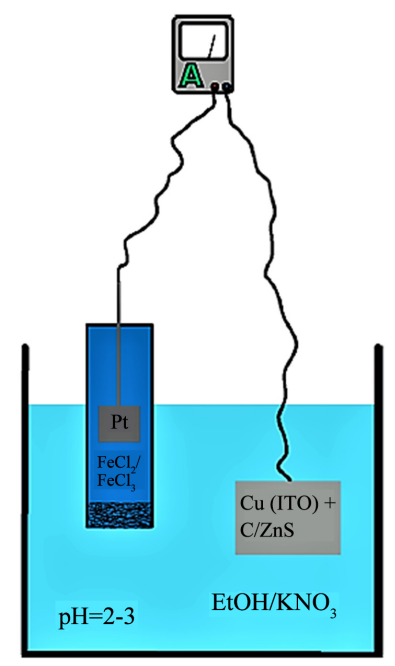

Figure 20. Schematic of an ethanol fuel cell using $\mathrm{ZnS}$ nanoparticles as a catalyst and a $\mathrm{FeCl}_{3} / \mathrm{FeCl}_{2}$ counter electrode [24].
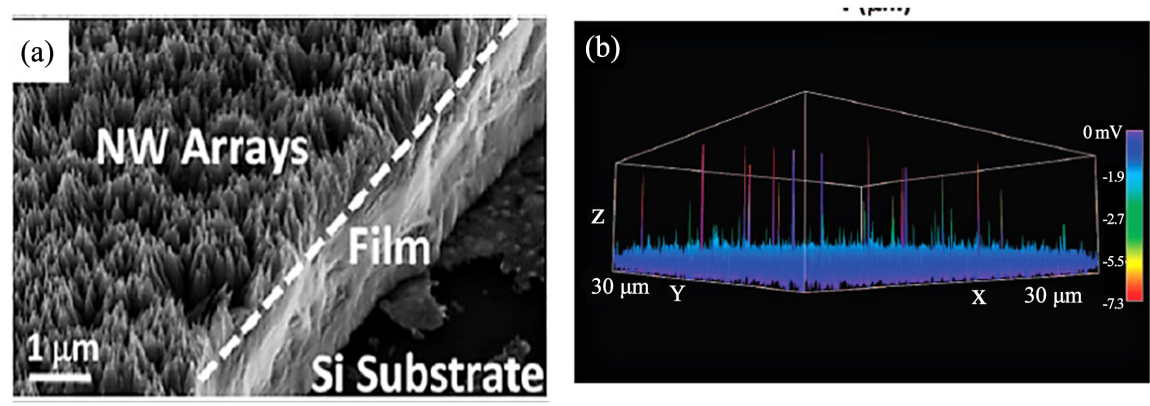

Figure 21. (a) $\mathrm{ZnO}-\mathrm{ZnS}$ nanowire arrays were grown vertically on a buffer layer, and (b) its three-dimensional vol tage output image received after an AFM scan across a heterostructure $\mathrm{ZnO}-\mathrm{ZnS}$ nanowire arrays with an area of $30 \times 30 \mu \mathrm{m}^{2}$ [26]. 


\subsection{Electroluminescence}

Amongst various useful properties of $\mathrm{ZnS}$, EL deserves a special mention, because $\mathrm{ZnS}$ is considered to be one of the best semiconducting functional materials for EL devices. EL is a phenomenon in which a material emits light in response to an electric current passed through it. This is one of the few instances in which a direct conversion of electric energy into visible light takes place without the generation of heat (incandescence), chemical reaction (chemiluminescence), or a mechanical action (mechanoluminescence). It was observed that if $\mathrm{ZnS}$ slightly doped with $\mathrm{Cu}$ suspended in an insulator and an intense alternating electric field was applied with capacitor like electrodes, visible light was emitted. The reason is when a sufficiently high voltage is applied across the electrodes, electrons that are trapped at between the interfaces layers are injected into the conduction band where they are accelerated by the field and may create excitation at the luminescent dopant centers by impact excitation and ionization mechanisms. This has led to a surge in research activities of EL properties of $\mathrm{ZnS}$, which were mostly undertaken on single-crystals and powder samples [10]. The light output of thin-film electroluminescent displays has been very reliable, with little loss after tens of thousands of hours of operation.

\subsection{Humidity Sensors}

Humidity sensor technologies enable to widespread application in electronic control systems are becoming ever more important. A little attention has been paid to humidity sensors based on metal chalcogenides. Recently, the applications of the ZnS:Al NWs as high-sensitive humidity sensors has been investigated [27]. This shows that when the $\mathrm{RH}$ value is beneath $50 \%$, the resistance of the ZnS:Al NW slightly increases with increasing $\mathrm{RH}$ value, while further increase of the RH value resulted in an obvious decrease of the resistance. To interpret the resistance increase at $\mathrm{RH}<50 \%$, a surface charge transfer model is proposed: due to the chemical adsorption of water molecules, $\mathrm{OH}$ - ions are likely formed on the ZnS:Al NW surface by capturing free electrons from the NWbulk [28]. The surface negative charges make the NW surface energy bands bending upwards, hence the holes will accumulate near the surface. A portion of the electrons in NW is compensated by the excess holes, and as a result, the NW resistance increases. Both electrical transfer measurements performed at 30\% and 70\% RHs show pronounced n-type conduction except the slight increase in the leakage current (IGS), indicating that the physical adsorption instead of the chemical adsorption dominates the conduction and finally contributes to the decrease of the resistance at higher humidity. Besides this, the humidity sensing capability and electrical resistance of $\mathrm{ZnS}$ nanowires at different relative humidity conditions have been investigated at room temperature [29]. Figure 22(a) is the schematic diagram of the resistance measurement of $\mathrm{ZnS}$ nanowires. When the $\mathrm{RH}$ percentage increases, a very small decreasing change was observed in the resistance value up to $55 \% \mathrm{RH}$. After this value, the resistance of $\mathrm{ZnS}$ nanowires 
decreases rapidly with exhibiting nearly linear behavior, as shown in Figure 22(b). The sensitivity increases about 1000 times from 33\% - 100\% RH depending on decreasing the resistance of $\mathrm{ZnS}$ nanowires. Also, $\mathrm{ZnS}$ nanowires have a porous surface, provide more surfaces for adsorption, resulting in enhanced sensitivity. This indicates $\mathrm{ZnS}$ nanowires have a great potential for humidity sensing applications at room temperature [30].

\subsection{Solar Cell}

$\mathrm{ZnS}$ nanostructure is being intensely used in the novel solar cell such as dye-sensitized solar cells (DSSCs), quantum dot-sensitized solar cells (QDSCs), $\mathrm{Cu}$ (In, Ga) $\mathrm{Se}_{2}$ (CIGS)-based thin film solar cells or organic-inorganic hybrid solar cells. Generally, ZnS nanostructure may be used as photoanode in DSSC, but the cell efficiency is too low that constitutes less than $1 \%$. For increasing the efficiency of $\mathrm{ZnO} / \mathrm{ZnS}$ core-shell, it was proposed that the $\mathrm{ZnS}$ layer on the $\mathrm{ZnO}$ nanowires suppressed the recombination of injected electrons at anode/electrolyte interface by reducing defect site.

One of the most promising thin film solar cells with high world rank efficiency is $\mathrm{Cu}$ (In, Ga) $\mathrm{Se}_{2}$ (CIGS)-based thin film solar cells. As presented in Figure 23. The device structure of CIGS solar cell is quite complex which consist of a multilayer of metal, semiconductor, and alloy layer. Typically, CdS has been applied as a buffer layer between the absorber and front contact layer for CIGS solar cells. Because of the incompatibility deposition method and environmental unfriendly of Cadmium is a matter of concern in large-scale solar cell production. On the other hand, ZnS Buffer layer can be fabricated by a various deposition method. By using a CBD-ZnS buffer layer, the conversion efficiency of $18.1 \%$ for Cd-free CIGS thin film solar cells has achieved which controlled by $\mathrm{O} / \mathrm{S}$ atomic ratio to minimize the conduction band offset at ZnS/CIGS interface and bulk recombination of those wide-gap alloys [31].

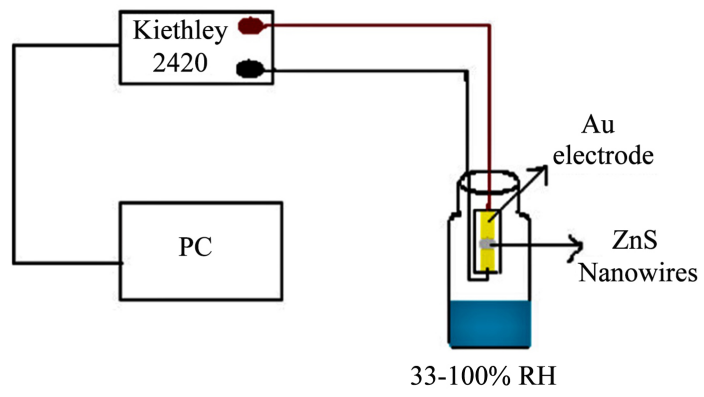

(a)

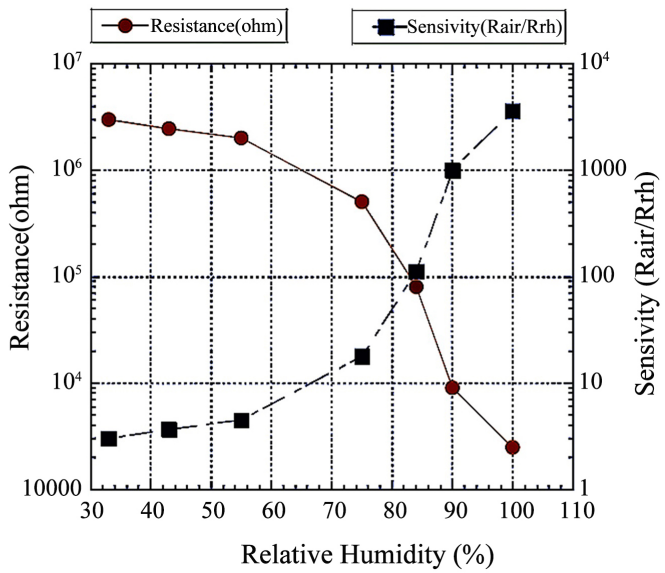

(b)

Figure 22. (a) The schematic diagram of resistance measurement of $\mathrm{ZnS}$ nanowires under varying relative humidity from 33\% - 100\%; (b) The variation in resistance and sensitivity of ZnS nanowires depending on varying relative humidity [29]. 


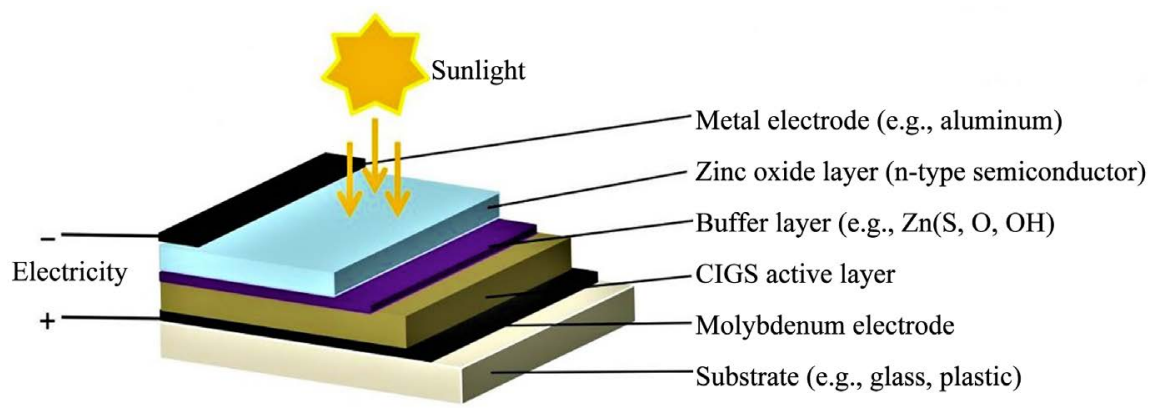

Figure 23. Configuration of a typical CIGS solar cell.

\subsection{Chemical Sensors}

Nanowires and nanoparticles are small in size where a few chemical molecules give a sufficient amount of change in electrical and optical properties for sensing application. As an optoelectronic semiconductor, $\mathrm{ZnS}$ has chemical sensing application. Compound semiconductor/insulator (ZnS/silica) core/shell nanocables have been synthesized using vapor-liquid-solid growth and used them to fabricate single nanowire-based FETs. After chemical modification, amine- and oxide-functionalized nanocables exhibit linear $\mathrm{pH}$ dependent conductance. The conductance of the $\mathrm{ZnS} /$ silica nanocable-based FET was modulated by an applied gate, and the surface of the silica shell was modified with 3-aminopropyltriethoxysilane (APTES) to provide a surface that could undergo protonation and deprotonation. The changes in the surface charge could chemically gate the nanocable-based transistors. The concept of a $\mathrm{pH}$ Nanosensor is illustrated in Figure 24(a). Measurements of the conductance as a function of time and $\mathrm{pH}$ demonstrate that the conductance increases in steps in accord with the $\mathrm{pH}$ values, as shown in Figure 24(b). In Figure 24(c) a representative curve of the conductance as a function of $\mathrm{pH}$ suggests that a modified $\mathrm{ZnS} /$ silica nanocable can be functionalized as a nanoscale $\mathrm{pH}$ sensor since its $\mathrm{pH}$ dependence is linear [22].

The proposed mechanism for $\mathrm{pH}$ sensing is described as follows. Covalently linking APTES to the oxide surface of nanocable results in a surface terminating in both $-\mathrm{NH}_{2}$ and $-\mathrm{SiOH}$ groups Figure 24(b), which have different dissociation constants, $\mathrm{pKa}$. At a high $\mathrm{pH}$ value, $-\mathrm{SiOH}$ is deprotonated to $-\mathrm{SiO}-$ on the surface of the silica shell and acts as a negative gate, which depletes electron carriers in the n-type $\mathrm{ZnS}$ core and decreases the conductance. At low $\mathrm{pH}$, the $-\mathrm{NH}_{2}$ group is protonated to $-\mathrm{NH}^{3+}$ and acts as a positive gate, which correspondingly causes an increase in conductance. The observed linear response can be attributed to an approximately linear change in the total surface charge density due to the combined acid and base behavior of both surface groups.

\subsection{Biosensors}

Biosensor is a device for the detection of an analyte that combines a biological component with a physicochemical detector component. $\mathrm{ZnS}$ nanomaterials 
with a spin coating method fabricated into Nafion / uricase /ZnS/ITO electrodes which have been successfully applied for electrochemical and photoelectrochemical UA (uric Acid detection in aqueous solution. The ZnS urchin-like nanostructures based electrochemical biosensor showed the highest sensitivity of $76.12 \mu \mathrm{A} \cdot \mathrm{cm}^{-2} \cdot \mathrm{mM}^{-1}$ with wide linear detection ranges from $0.01 \mathrm{mM}$ to 1.7 $\mathrm{mM}$ also meets the requirements for diagnosis in the clinic. Using irradiation of $300 \mathrm{~nm} \mathrm{UV}$, its sensitivity of detecting UA is increased 5 times, reaching $413.98 \mu \mathrm{A} \cdot \mathrm{cm}^{-2} \cdot \mathrm{mM}^{-1}$, which is higher than that of most electrochemical biosensors. However, the linear range is decreased to $0.01-0.54 \mathrm{mM}$, which is to be improved in future work. These results provide a simple and efficient approach to fabricate $\mathrm{ZnS}$ based electrochemical and photoelectrochemical biosensors [32].

A detection method of DNA hybridization based on labeling with $\mathrm{ZnS}$ QD tracers has been developed with electrochemical-stripping measurements of the nanoparticles. A DNA sensing mechanism was developed by the measurement of I-V and FET transfer characteristics [33]. The ZnS/SWNTs FET was formed by using the highly doped silicon substrate as a back gate and is schematically represented in Figure 25(a). The properties compared to two SWNT device with and without $\mathrm{ZnS}$ nanocrystals. The comparison did not do any significant change in current resistance because of no hybridization due mismatch of nc-ssDNA sequence with the probe ss-DNA. Moreover, Figure 25(b) shows a calibration curve where the ZnS/SWNT-ssDNA device exhibited about 2.5-fold increase in sensitivity of 0.16 per-decade PM c-ssDNA over SWNT ssDNA device showing a sensitivity of 0.06 per decade pM c-ssDNA. This significant increase in sensitivity toward c-ssDNA hybridization may be attributed to an increased loading of $\mathrm{NH}_{2}$-ssDNA probe over $\mathrm{ZnS}$ nanocrystals due to their large surface to volume ratio and a subsequent transfer of negative charge electrons to SWNT upon hybridization with c-ssDNA [33].

\subsection{Gas Sensor}

$\mathrm{ZnS}$ has rarely been used as gas sensors because of its low carrier density and irreversible reaction with oxygen which can be removed by using ultraviolet (UV) illumination. The illumination enhances the modulation of conductance by absorbed oxygen. $\mathrm{ZnS}$ nanobelts have fabricated using a thermal evaporation and the response of $\mathrm{ZnS}$ nanobelts to different oxygen pressures without or with UV illumination was measured. The current increased from 0.21 to $1.71 \mathrm{nA}$ within $0.4 \mathrm{~s}$ and then at a relatively slow rate to $2.30 \mathrm{nA}$ in $2.65 \mathrm{~s}$. When the light was turned off, the current recovered to the original dark level within $0.2 \mathrm{~s}$. The reason is when a $\mathrm{ZnS}$ nanobelt is exposed to UV illumination, the carrier density increases because of the electron-hole pair generation. The chemisorbed oxygen ions combined with the photoexcited holes. This result in desorption of oxygen species on the surface of $\mathrm{ZnS}$ nanobelt. Both processes enhance the conductance of the belt. In a logarithmic scale, the dark level conductance of $\mathrm{ZnS}$ nanobelt 
varied slightly from $9.8 \times 10^{-12}$ to $1.08 \times 10^{-11} \mathrm{~S}$ without UV illumination and decreased from $1.13 \times 10^{-10}$ to $0.13 \times 10^{-10} \mathrm{~S}$ as the oxygen pressure increased from $3 \times 10^{-3}$ to $1 \times 10^{5} \mathrm{~Pa}$ under UV illumination. From the above results, the conductance of the $\mathrm{ZnS}$ nanobelt is roughly proportional to the logarithm of the oxygen pressure, which indicates that these nanobelts can be promising oxygen sensors [34].

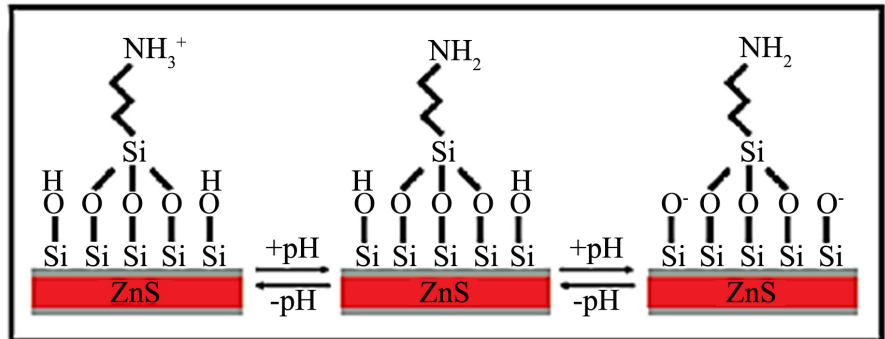

(a)

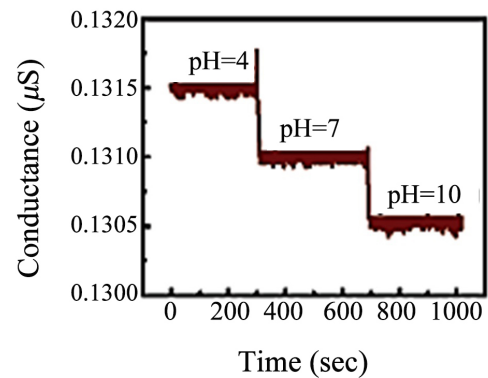

(b)

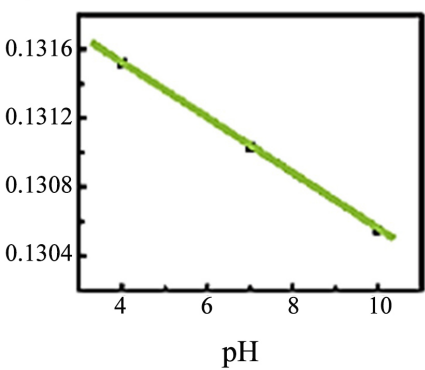

(c)

Figure 24. (a) Schematic illustrating a nanocable-based sensor for $\mathrm{pH}$ detection. The APTES-modified $\mathrm{ZnS} /$ silica nanocable changes in the surface charge state with $\mathrm{pH}$ due to $-\mathrm{NH}_{2}$ and $-\mathrm{SiOH}$ groups; (b) Real-time detection of the proposed mechanism for $\mathrm{pH}$ sensing is described as follows. Covalently linking APTES to the oxide surface of a conductance for an APTE modified nanocable; (c) The plot of the conductance versus $\mathrm{pH}$; the points are experimental data, and the solid line is a linear fit through the experimental data [22].

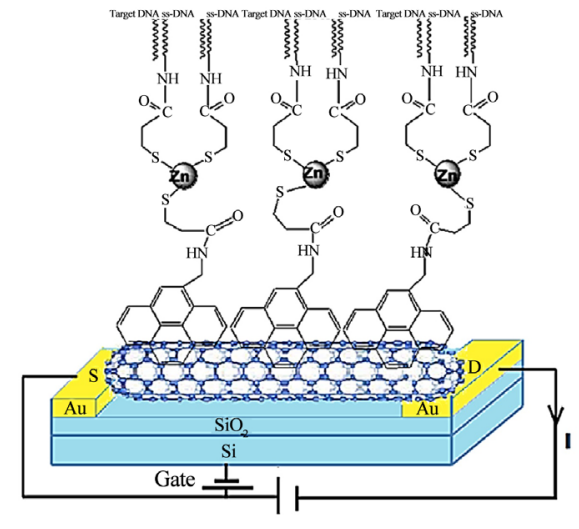

(a)

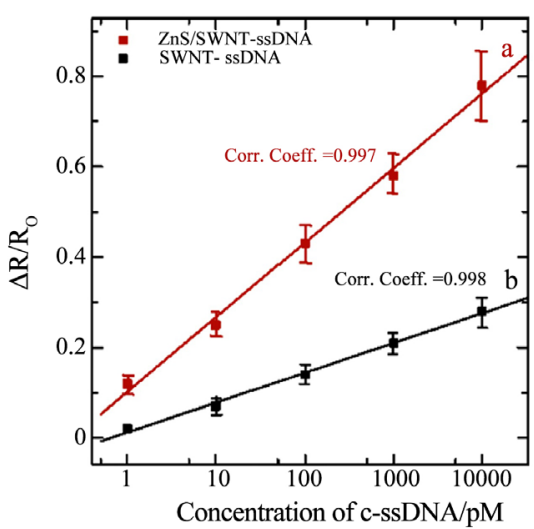

(b)

Figure 25. (a) Schematic cross-section of the ZnS/SWNT FET device. (b) Calibration curve of (a) ZnS/SWNT-ssDNA and (b) SWNT-ssDNA sensor for complimentary DNA (c-ssDNA) [32]. 


\subsection{UV Light Sensor}

Ultraviolet ray (UV) is the electromagnetic radiation of 10 - $400 \mathrm{~nm}$ wavelength with energy ranges from $3 \mathrm{eV}$ to $124 \mathrm{eV}$. ZnS provides $\mathrm{UV}$ detectors that would particularly well serve within the UV-A (320 - $400 \mathrm{~nm}$ ) band. The high spectral selectivity combined with the high photosensitivity implies the bright prospects of using the ZnS nanobelts as "visible-blind" UV photodetectors in many areas [35]. The direct bandgap makes $\mathrm{ZnS}$ a promising material for fabricating optoelectronic devices. In Figure 26 typical SEM images show that the nanobelts can grow up to a millimeter in length. TEM observation reveals that $\mathrm{ZnS}$ nanostructure has the belt-like geometry and transparency. The typical width of nanobelts is in the range of $200 \mathrm{~nm}$ to $1 \mu \mathrm{m}$ were also observed. All of these phenomena indicate that the individual \& multiple $\mathrm{ZnS}$ nanostructure can be used as "visible-blind" UV light photodetector with high sensitivity, selectivity and fast time response.

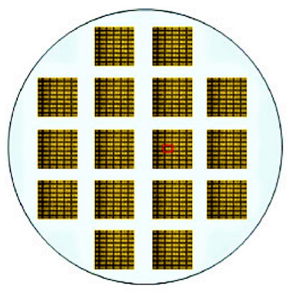

(a)

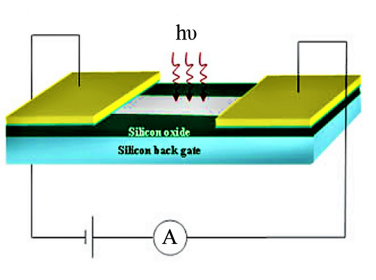

(b)

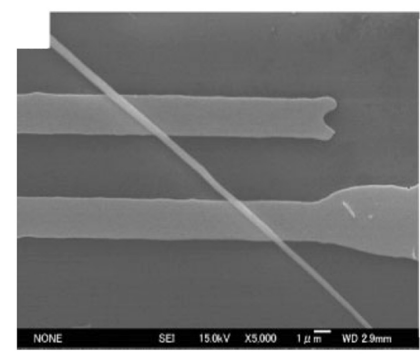

(c)

Figure 26. (a) An optical micrograph of an individual ZnS nanobelt-based UV sensor array composed of individual structures. (b) and (c) A schematic illustration of an individual $\mathrm{ZnS}$ nanobelt configured as a photodetector and a representative SEM image of a single-crystalline $\mathrm{ZnS}$ nanobelt device.

\section{Conclusions}

In this review work, as a doping element $\mathrm{Cu}$ shows the lowest bandgap that is $3.47 \mathrm{eV}$ and its crystallite size is also suitable which constitutes $11 \mathrm{~nm}$ for $5 \%$ concentration. Small crystallite size produces uniform, dense and homogenous surface which is one of the most important requirements for the deposition of the ultrathin film. On the other hand, all of the doping elements show that transmittance decreased with increasing concentration because of higher absorption. But in the range of transmission $60 \%-80 \%$ which could be used in various applications of $\mathrm{ZnS}$ such as sensors. Moreover $\mathrm{ZnS}: \mathrm{Cu}^{2+}$ with effective surfactants such as TOPO, SHMP, PEG shows that it helps to reduce crystal size and eliminate defects. Among the surfactants the TOPO molecules are completely covered the $\mathrm{ZnS}: \mathrm{Cu}^{2+}$ surface and crystallinity is improved. This result indicates the potential applications of the surfactant-capped $\mathrm{ZnS}: \mathrm{Cu}^{2+}$ nanoparticles in nanoscale fluorescent probes for biological and medical applications. Ultrafine $\mathrm{ZnS}$ is a mixture of commercial $\mathrm{ZnS}$ powder, while $\mathrm{C}$ powder and $\mathrm{S}$ powder are successful as a field emitter. Catalytic activities give helps $\mathrm{CO}_{2}$ 
reduction with $\mathrm{ZnS}$ suspension. As a buffer layer in CIGS solar cell, $\mathrm{ZnS}$ is more efficient then CdS which upholds $18.1 \%$ of efficiency. The conductance of $\mathrm{ZnS}$ nanobelts as a function of oxygen pressure in logarithmic scale utilized as a gas sensor. ZnS/silica FETs were used for biological sensing and fuel cells are used for mobile electricity generation. ZnS nanowires have a great potential for nanogenerator as well as humidity sensing applications. It is also considered as the most suitable candidates for EL devices.

From our understanding of above study is not a complete outcome for $\mathrm{ZnS}$ rather than some partially interpretation of $\mathrm{ZnS}$ as recent analysis. Therefore, for a complete report on $\mathrm{ZnS}$ study needed a wide variety of comparison by taking most possible elements doping on $\mathrm{ZnS}$. Which demands more precise experimental data and finding them from numerous article is a challenging criterion. However more work on turning the $\mathrm{ZnS}$ conductivity, bandgap, surface, and optical properties in a more controllable way can give those precise data. And this will facilitate the most conceivable development of applications for sensors, FET, LEDs, Solar cell and other optoelectronic devices based on $\mathrm{ZnS}$ nanostructures. Eventually, for technological applications of $\mathrm{ZnS}$ thin film synthesis, positioning and interconnection of these building blocks are needed for the direct integration. Also, a reliable post-assembly process of nanostructures is necessary to implement them in a well-established manufacturing process.

\section{Conflicts of Interest}

The authors declare no conflicts of interest regarding the publication of this paper.

\section{References}

[1] Rahman, M.K., Nemouchi, F., Chevolleau, T., Gergaud, P. and Yakache, K. (2017) $\mathrm{Ni}$ and Ti Silicide Oxidation for CMOS Applications Investigated by XRD, XPS and FPP. Materials Science in Semiconductor Processing, 71, 470-476. https://doi.org/10.1016/j.mssp.2017.06.025

[2] Harish, K.N., Bhojya Naik, H.S., Prashanth Kumar, P.N. and Viswanath, R. (2012) Synthesis, Enhanced Optical and Photocatalytic Study of Cd-Zn Ferrites under Sunlight. Catalysis Science \& Technology, 2, 1033-1039. https://doi.org/10.1039/c2cy00503d

[3] Viswanath, R., Seethya, H., Naik, B., Somalanaik, Y.K.G., et al. (2014) Studies on Characterization, Optical Absorption, and Photoluminescence of Yttrium Doped ZnS Nanoparticles. Journal of Nanotechnology, 2014, Article ID: 924797. https://doi.org/10.1155/2014/924797

[4] Harish, K.N., BhojyaNaik, H.S., Prashanth Kumar, P.N. and Viswanath, R. (2013) Remarkable Optical and Photocatalytic Properties of Solar Light Active Nd-Substituted Ni Ferrite Catalysts: For Environment Protection. ACS Sustainable Chemistry \& Engineering, 1, 1143-1153. https://doi.org/10.1021/sc400060z

[5] Goldman, E.R., Balighian, E.D., Kuno, M.K., et al. (2002) Luminescent Quantum Dot-Adaptor Protein-Antibody Conjugates for Use in Fluoroimmunoassays. Physica Status Solidi B, 229, 407-414. https://doi.org/10.1002/1521-3951(200201)229:1<407::AID-PSSB407>3.0.CO;2-S

[6] Wang, L., Xu, X. and Yuan, X. (2010) Preparation and Photoluminescent Properties 
of Doped Nanoparticles of ZnS by Solid-State Reaction. Journal of Luminescence, 130, 137-140. https://doi.org/10.1016/j.jlumin.2009.07.036

[7] Ramasamy, V., Praba, K. and Murugadoss, G. (2012) Synthesis and Study of Optical Properties of Transition Metals Doped ZnS Nanoparticles. Spectrochimica Acta A, 96, 963-971. https://doi.org/10.1016/j.saa.2012.07.125

[8] Nguyen, T.T., Trinh, X.A., Nguyen, L.H. and Pham, T.H. (2011) Photoluminescence Characteristics of As-Synthesized and Annealed ZnS:Cu, Al Nanocrystals, Advances in Natural Sciences. Nanoscience and Nanotechnology, 2, Article ID: 035008.

[9] Kasap, S. and Capper, P. (2007) 16. Wide-Bandgap II-VI Semiconductors: Growth and Properties. In: Springer Handbook of Electronic and Photonic Materials, Springer US, Berlin, 325-342.

[10] Fang, X.S., Zhai, T.Y., Gautam, U.K., Li, L., Wua, L., Bando, Y. and Golberg, D. (2011) ZnS Nanostructures: From Synthesis to Applications. Progress in Materials Science, 56, 175-287. https://doi.org/10.1016/j.pmatsci.2010.10.001

[11] Hwang, D.H., Ahn, J.H., Hui, K.N., Hui, K.S. and Son, Y.G. (2012) Structural and Optical Properties of ZnS Thin Films Deposited by RF Magnetron Sputtering. Nanoscale Research Letters, 7, 26. https://doi.org/10.1186/1556-276X-7-26

[12] Drobyshevski, E.M. (2000) In Searches for Daemons. Physics of Atomic Nuclei, 63, 1037-1041. https://doi.org/10.1134/1.855745

[13] Rahman, M.K., Marchand, R. and Neher, B. (2015) A Study of the Replacement of Materials in Smart Card. Materials Sciences and Applications, 3, 773-782. https://doi.org/10.4236/msa.2015.69079

[14] Aslan, G.F. and Tumbul, A. (2015) Nanostructured Cu-Doped ZnS Polycrystalline Thin Films Produced by a Wet Chemical Route: The Influences of Cu Doping and Film Thickness on the Structural, Optical and Electrical Properties. Journal of Sol-Gel Science and Technology, 75, 45-53. https://doi.org/10.1007/s10971-015-3674-8

[15] Murugadoss, G. (2013) Synthesis and Photoluminescence Properties of Zinc Sulfide Nanoparticles Doped with Copper Using Effective Surfactants. Particuology, 11, 566-573. https://doi.org/10.1016/j.partic.2012.11.003

[16] Shiv, P., Patel, J.C., Pivin, R., Chandra, D. and Kanjilal, L.K. (2015) Ferromagnetism in Ni Doped ZnS Thin Films: Effects of Ni Concentration and Swift Heavy Ion Irradiation. Vacuum, 111, 150-156. https://doi.org/10.1016/j.vacuum.2014.10.010

[17] Akhtar, M.S., Alghamdi, Y.G., Malik, M.A., Khalil, R.M.A., Riaz, S. and Naseem, S. (2015) Structural, Optical, Magnetic and Half-Metallic Studies of Cobalt Doped ZnS Thin Films Deposited via Chemical Bath Deposition. Journal of Materials Chemistry $C$, 3, 6755-6763. https://doi.org/10.1039/C5TC00557D

[18] Kumar, S. and Verma, N.K. (2015) Structural, Optical and Magnetic Investigations on Fe-Doped ZnS Nanoparticles. Journal of Materials Science: Materials in Electronics, 26, 2754-2759. https://doi.org/10.1007/s10854-015-2755-3

[19] Fang, X.S., Ye, C.H., Zhang, L.D., Wang, Y.H. and Wu, Y.C. (2005) Temperature-Controlled Catalytic Growth of ZnS Nanostructures by the Evaporation of ZnS Nanopowders. Advanced Functional Materials, 15, 63-68.

https://doi.org/10.1002/adfm.200305008

[20] Liang, C.H., Shimizu, Y., Sasaki, T., Umehara, H. and Koshizaki, N. (2004) Au-Mediated Growth of Wurtzite ZnS Nanobelts, Nanosheets, and Nanorods via Thermal Evaporation. The Journal of Physical Chemistry B, 108, 9728-9733. https://doi.org/10.1021/jp037963f 
[21] Fang, X.S., Bando, Y., Shen, G.Z., Ye, C.H., Gautam, U.K., Costa, P.M.F.J., et al. (2007) Ultrafine ZnS Nanobelts as Field Emitters. Advanced Materials, 19, 2593-2596. https://doi.org/10.1002/adma.200700078

[22] He, J.H., Zhang, Y.Y., Liu, J., Moore, D., Bao, G. and Wang, Z.L. (2007) ZnS/Silica Nanocable Field Effect Transistors as Biological and Chemical Nanosensors. Journal of Materials Chemistry C, 111, 12152-12156. https://doi.org/10.1021/jp074772u

[23] Hu, J.S., Ren, L.L., Guo, Y.G., Liang, H.P., Cao, A.M., Wan, L.J., et al. (2005) Mass Production and High Photocatalytic Activity of ZnS Nanoporous Nanoparticles. Angewandte Chemie International Edition, 44, 1269-1273. https://doi.org/10.1002/anie.200462057

[24] Bredol, M. and Kaczmarek, M. (2010) Potential of Nano-ZnS as an Electrocatalyst. The Journal of Physical Chemistry A, 114, 3950-3955. https://doi.org/10.1021/jp907369f

[25] Wang, Z.L. and Song, J.H. (2006) Piezoelectric Nanogenerators Based on Zinc Oxide Nanowire Arrays. Science, 312, 242-246. https://doi.org/10.1126/science.1124005

[26] Yu, M.Y., Song, J.H., Lu, M.P., Lee, C.Y., Chen, L.J. and Wang, Z.L. (2009) $\mathrm{ZnO}-\mathrm{ZnS}$ Heterojunctions and $\mathrm{ZnS}$ Nanowire Arrays for Electricity Generation. ACS Nano, 3, 357-362. https://doi.org/10.1021/nn800804r

[27] Jiang, P., Jie, J.S., Yu, Y.Q., Wang, Z., Xie, C., Zhang, X.W., Wu, C.Y., Wang, L., Zhu, Z.F. and Luo, L.B. (2012) Aluminium-Doped n-Type ZnS Nanowires as High-Performance UV and Humidity Sensors. Journal of Materials Chemistry, 22, 6856-6861. https://doi.org/10.1039/c2jm15365c

[28] Jie, J.S., Zhang, W.J., Peng, K.Q., Yuan, G.D., Lee, C.S. and Lee, S.T. (2008) Surface-Dominated Transport Properties of Silicon Nanowires. Advanced Functional Materials, 18, 3251-3257. https://doi.org/10.1002/adfm.200800399

[29] Zar, N.U., Okur, S. and Arıkan, M.C. (2011) Investigation of Humidity Sensing Properties of ZnS Nanowires Synthesized by Vapor Liquid Solid (VLS) Technique. Sensors and Actuators A: Physical, 167, 188-193.

[30] Wang, X.F., Huang, H.T., Liang, B., Liu, Z., Chen, D. and Shen, G.Z. (2013) ZnS Nanostructures: Synthesis, Properties and Applications. Critical Reviews in Solid State and Materials Sciences, 38, 57-90. https://doi.org/10.1080/10408436.2012.736887

[31] Ummartyotin, S. and Infahsaeng, Y. (2016) A Comprehensive Review on ZnS: From Synthesis to an Approach on Solar Cell. Renewable and Sustainable Energy Reviews, 55, 17-24. https://doi.org/10.1016/j.rser.2015.10.120

[32] Zhao, Y., Wei, X.Y., Peng, N.C., Wang, J.H. and Jiang, Z.D. (2017) Study of ZnS Nanostructures Based Electrochemical and Photoelectrochemical Biosensors for Uric Acid Detection. Sensors, 17, 1235. https://doi.org/10.3390/s17061235

[33] Rajesh, Das, B.K., Srinives, S. and Mulchandani, A. (2011) ZnS Nanocrystals Decorated Single-Walled Carbon Nanotube Based Chemiresistive Label-Free DNA Sensor. Applied Physics Letters, 98, Article ID: 013701. https://doi.org/10.1063/1.3529951

[34] Liu, Y.G., Feng, P., Xue, X.Y., Shi, S.L., Fu, X.Q., Wang, C., et al. (2007) RoomTemperature Oxygen Sensitivity of ZnS Nanobelts. Applied Physics Letters, 90, Article ID: 042109. https://doi.org/10.1063/1.2432278

[35] Fang, X.S., Bando, Y., Liao, M.Y., Gautam, U.K., Zhi, C.Y., Dierre, B., et al. (2009) Single-Crystalline ZnS Nanobelts as Ultraviolet-Light Sensors. Advanced Materials, 21, 2034-2039. https://doi.org/10.1002/adma.200802441 